\title{
Structure and Variability of the Kuroshio Current in Tokara Strait*
}

\author{
Ming FENG + \\ International Pacific Research Center, SOEST, University of Hawaii, Honolulu, Hawaii \\ HUMio MitsuderA \\ International Pacific Research Center, SOEST, University of Hawaii, Honolulu, Hawaii, and \\ Frontier Research System for Global Change, Tokyo, Japan \\ YASUSHI YoshIKAWA \\ Japan Marine Science and Technology Center, Yokosuka, Japan
}

(Manuscript received 20 April 1999, in final form 3 November 1999)

\begin{abstract}
Four years of mooring array measurements in Tokara Strait, south of Kyushu, Japan, from 1992 to 1996 are used to analyze the structure and temporal variability of the Kuroshio Current. The mean Kuroshio current in Tokara Strait shows a nearly permanent subsurface double-core structure, possibly due to topographic blockage effects.

The dominant variations of the Kuroshio in Tokara Strait are separated into long-term variability (typically 100-day period) and short-term variability (10 days to 1 month) according to spectrum and wavelet analysis. The long-term variability has a large horizontal scale across the strait, with a striking twofold banded structure in spatial correlations. This is due to the north-south Kuroshio axis shift that advects the double-core structure of the mean current. The axis shift can be indexed with the northeastward current velocity at the northernmost station; a composite analysis using this index shows well-defined northward and southward axis shift structures of the Kuroshio current. From the composite of the TOPEX/Poseidon sea level anomaly in terms of this index, the Kuroshio axis shift and the current structure change are associated with a dipole-shape sea level anomaly east of Tokara Strait. On the other hand, the short-term variability of high kinetic energy only has a small horizontal scale within the northern part of the current, which is related to frontal variability.

There exists a deep southwestward undercurrent below $600 \mathrm{~m}$ in the northern part of Tokara Strait, flowing along the isobaths. The undercurrent becomes stronger during the northward shift of the Kuroshio axis, while it almost disappears during the southward shift.
\end{abstract}

\section{Introduction}

Tokara Strait is located near $130^{\circ} \mathrm{E}$ between Amamioshima and Tanegashima Islands south of Kyushu, Japan, with a northeast-southwest inclination (Fig. 1). The strait is the main pathway of the Kuroshio Current from the East China Sea (ECS) to the Pacific Ocean south of Japan (Nitani 1972; Nagata and Takeshita 1985). The variability of the Kuroshio position and vol-

\footnotetext{
* School of Ocean and Earth Science and Technology Contribution Number 5223 and IPRC Publication Number 21.

+ Current affiliation: Division of Marine Research, CSIRO, Hobart, Tasmania, Australia.
}

Corresponding author address: Dr. Humio Mitsudera, IPRC/ SOEST, University of Hawaii, Honolulu, HI 96822.

E-mail: humiom@soest.hawaii.edu ume transport in Tokara Strait is thought to be crucial in understanding the Kuroshio meander variations south of Japan (Masuda 1982; Chao 1984; Yasuda et al. 1985; Yamagata and Umatani 1989; Kawabe 1995).

From March 1992 to March 1996, moored observations were made at nine sites across the strait as a joint effort by the Japan Meteorological Agency, Meteorological Research Institute, Maritime Safety Agency, and Japan Marine Science and Technology Center (JAMSTEC), known as the Kuroshio Exploitation and Utilization Research (KER), and by Kagoshima University (Yamamoto et al. 1998). They are called "Tokara Strait Mooring Group." The mooring array spanned $143 \mathrm{~km}$ of Tokara Strait, with a current-resolving horizontal spacing of 11-28 km (Fig. 1). This was the first time that the Kuroshio current in the strait had been continuously monitored with long-term mooring array measurements. A major purpose of this observation was to examine whether the volume transport of the Kuroshio 

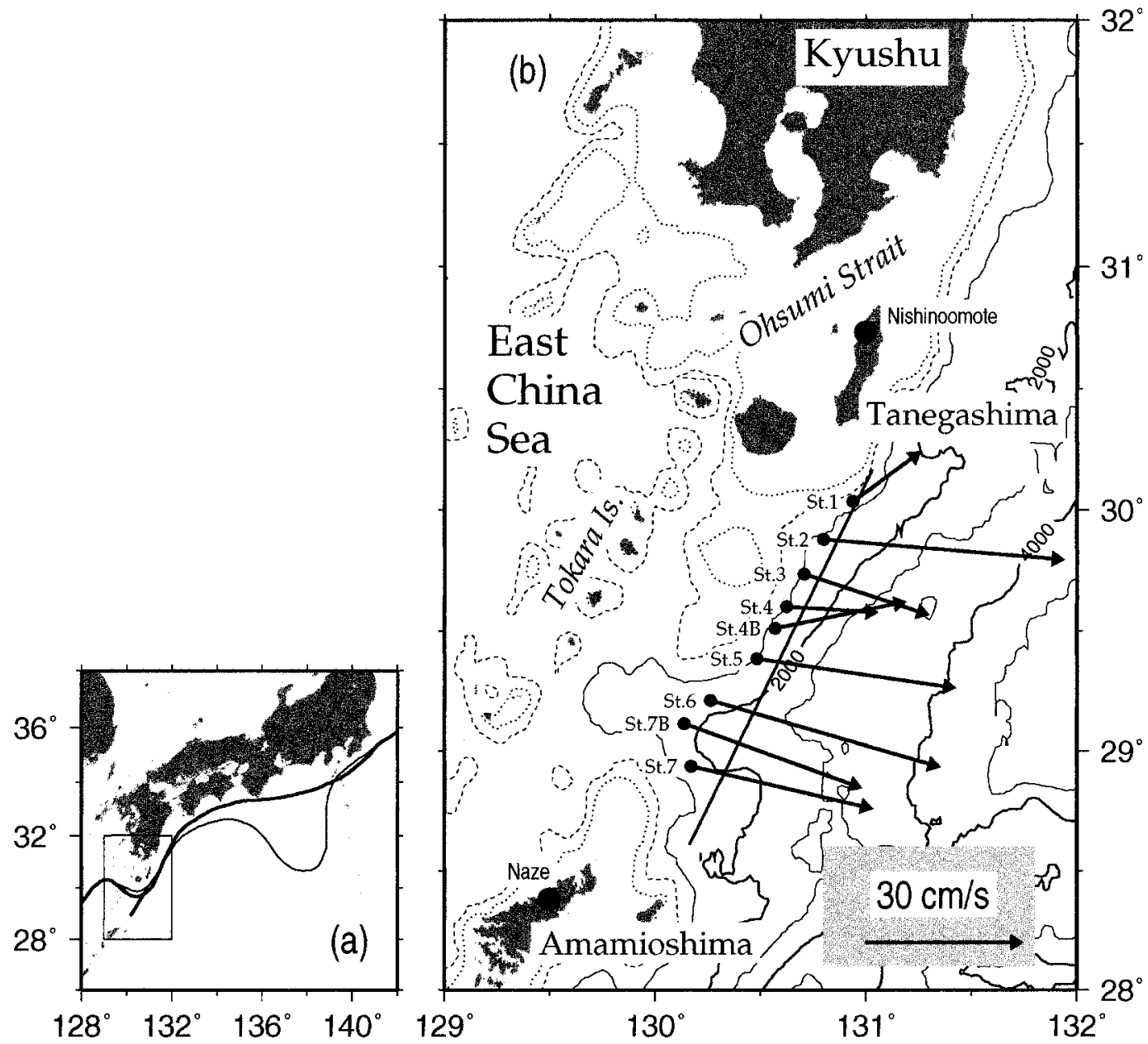

FIG. 1. (a) The typical Kuroshio large meander path (light curve) and nonlarge meander path (heavy curve) adopted from Kawabe (1995). The square box indicates the Tokara Strait region. (b) Bathymetry near Tokara Strait. Bathymetry data are obtained from the Japan Oceanographic Data Center. The dashed and dotted lines indicate 500-m and 300-m isobaths, respectively. The solid circles are the locations of the moorings and the arrows represent mean current velocity near 250-m depth at each mooring. The straight line indicates the location of a CTD section used in this study.

through the strait could be regarded as an index for the large meander formation. Unfortunately, a stationary, long-lived meander did not form during this period (Qiu and Miao 2000). Nevertheless, there were several transition processes from the straight path to the meandertype path that lasted for a few months. In the present study, we describe the variability of the Kuroshio obtained from the mooring array as a first step toward understanding Kuroshio path dynamics in relation to Kuroshio variability in Tokara Strait.

Many observation data have been used to describe the Kuroshio in Tokara Strait, such as the historical geomagnetic electrokinetograph (GEK) surface current data (Nitani 1972; Rikiishi and Sasaki 1988; Qiu et al. 1990), ferry boat and satellite sea surface temperature (SST) (Nagata and Takeshita 1985; Qiu et al. 1990; Akiyama et al. 1992), conductivity-temperature-depth (CTD) and acoustic Doppler current profiler (ADCP) sections (Bingham and Talley 1991; Nakano et al. 1994), sea level data from tidal stations (Kawabe 1988; Kutsuwada and Morikawa 1996), surface drifter data (Uchida et al. 1998), and short-term mooring data (Takematsu et al. 1986).

These observations reveal that the main body of the Kuroshio flows southeastward through the strait, then turns cyclonically toward the northeast, and from the shallow shelf in the ECS enters the deep ocean south of Japan, carrying low salinity surface coastal water, subtropic salinity maximum water, and low salinity North Pacific Intermediate Water (Nitani 1972). Different estimates of the Kuroshio volume transport through Tokara Strait range from 18 to $32 \mathrm{~Sv}\left(\mathrm{~Sv} \equiv 10^{6} \mathrm{~m}^{3} \mathrm{~s}^{-1}\right.$ : Bingham and Talley 1991; Nakano et al. 1994; Yamamoto et al. 1993; Yamamoto et al. 1998). The leakage of volume transport through Ohsumi Strait between 


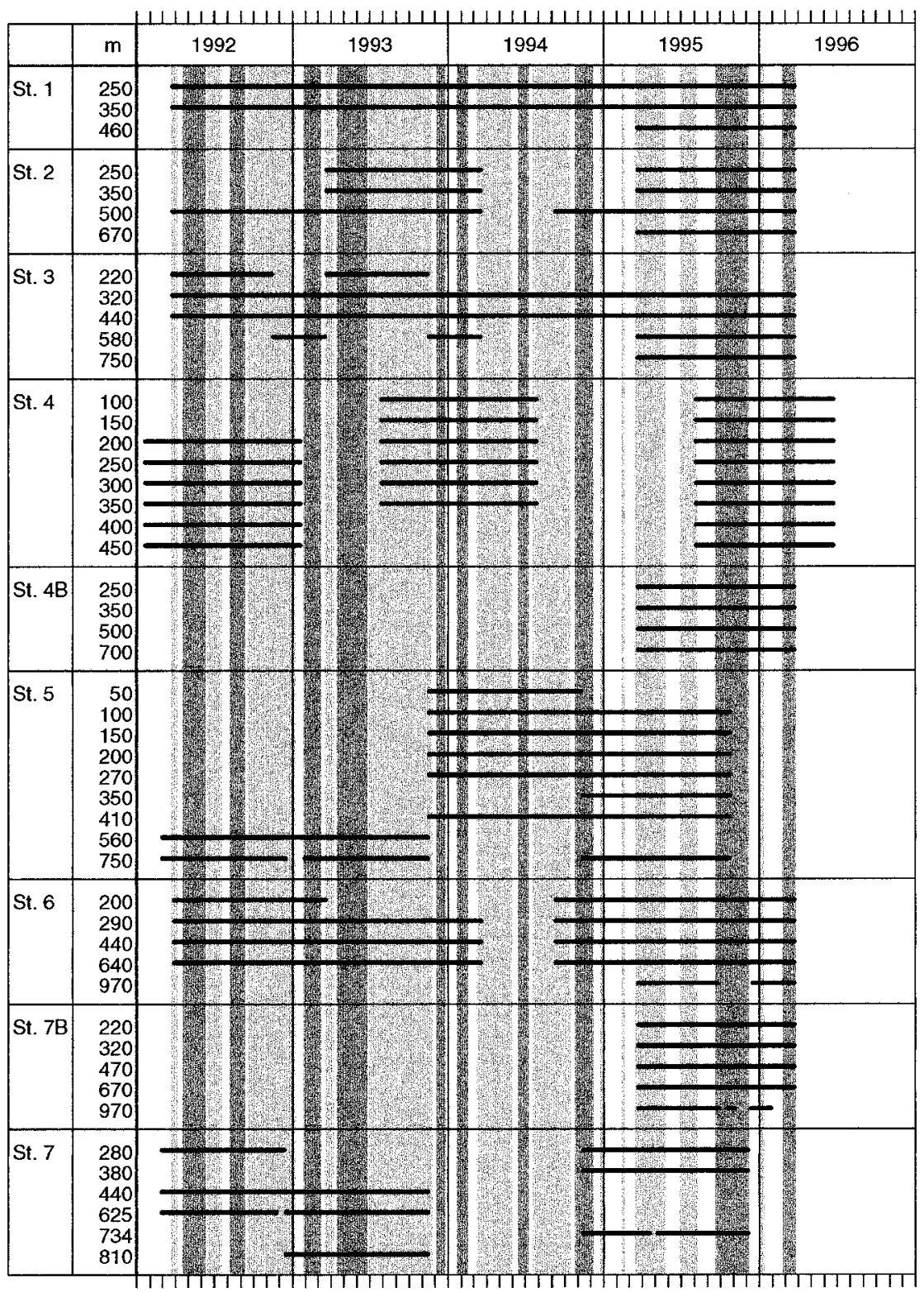

FIG. 2. Mooring depths and time coverage. The light (dark) shading indicates periods when the Kuroshio axis shifts southward (northward) determined by low-frequency northeast velocity component at the $250-\mathrm{m}$ depth level of station 1 (section $4 \mathrm{a}$ ).

Kyushu and Tanegashima is of much smaller magnitude because of shallow water depth.

The multicore structure of the Kuroshio current in Tokara Strait was noticed from previous inverse calculations (Bingham and Talley 1991; Nakano et al. 1994). A boundary at about $600 \mathrm{~m}$ between the Kuroshio and deep water flowing southwestward was identified on the inshore side of the strait (Kawabe 1980; Takematsu et al. 1986).

The Kuroshio showed a north-south shift of its northern front in Tokara Strait from a 3-yr record of ferry SST data (Nagata and Takeshita 1985). The timescale of the variability ranged from 20 to 60 days. However, only long period ( $>40$ days) fluctuations had large horizontal extent (Nagata and Takeshita 1985). Frequent observation of surface current by high-frequency radar and SST by a commercial ferry boat indicated that the current speed and direction around Tanegashima Island changed with the fluctuating path of the Kuroshio in the strait (Akiyama et al. 1992). Downstream propagation of 14-20 day frontal instability waves from the ECS was found to be related to the north-south shift of the surface front in the strait (Qiu et al. 1990). An 11-day wave was observed in the ECS with a downstream prop- 

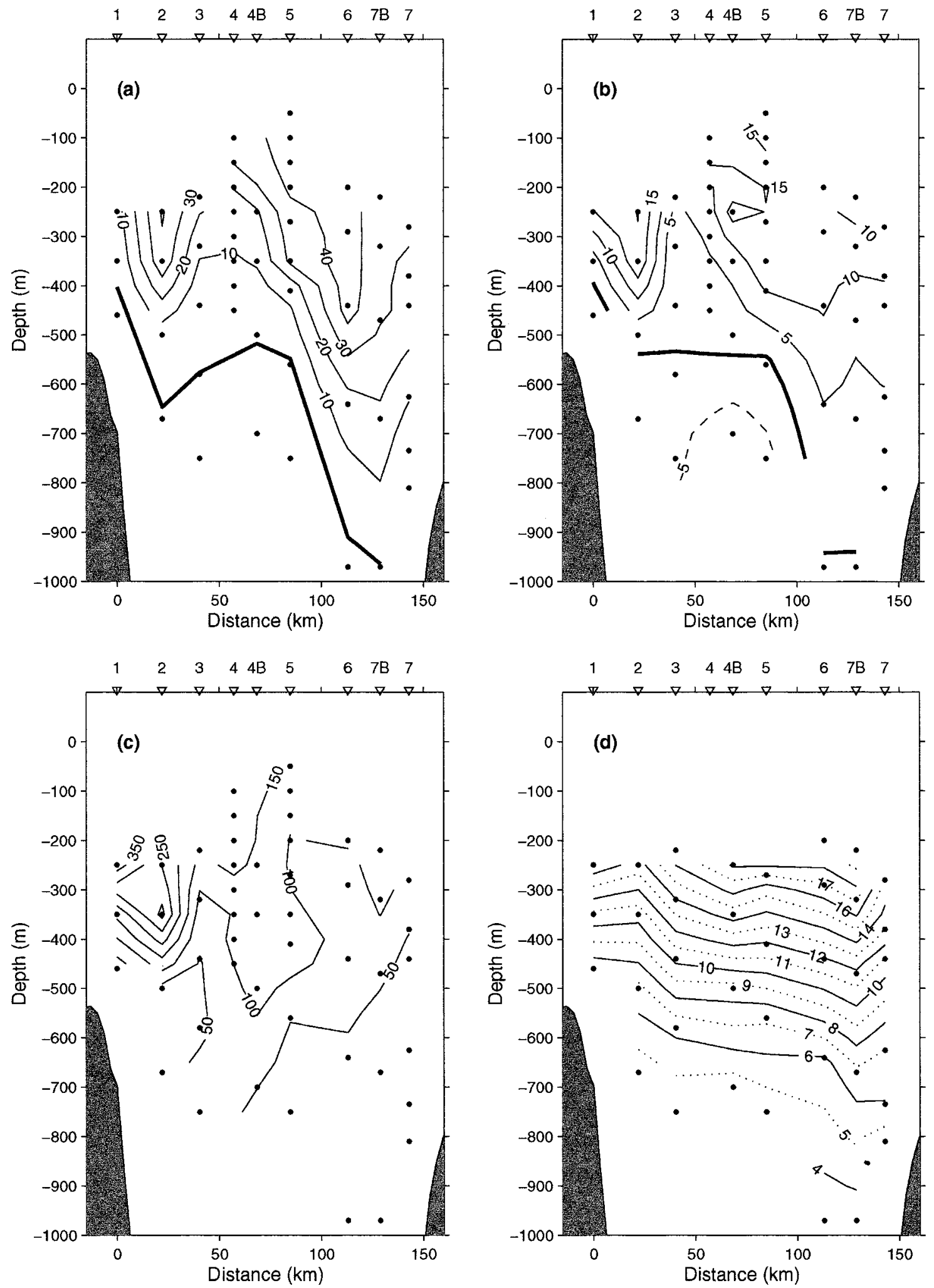

FIG. 3. The mean (a) alongstream and (b) cross-stream current velocity structure, (c) current velocity variance, and (d) mean temperature from the mooring data. 

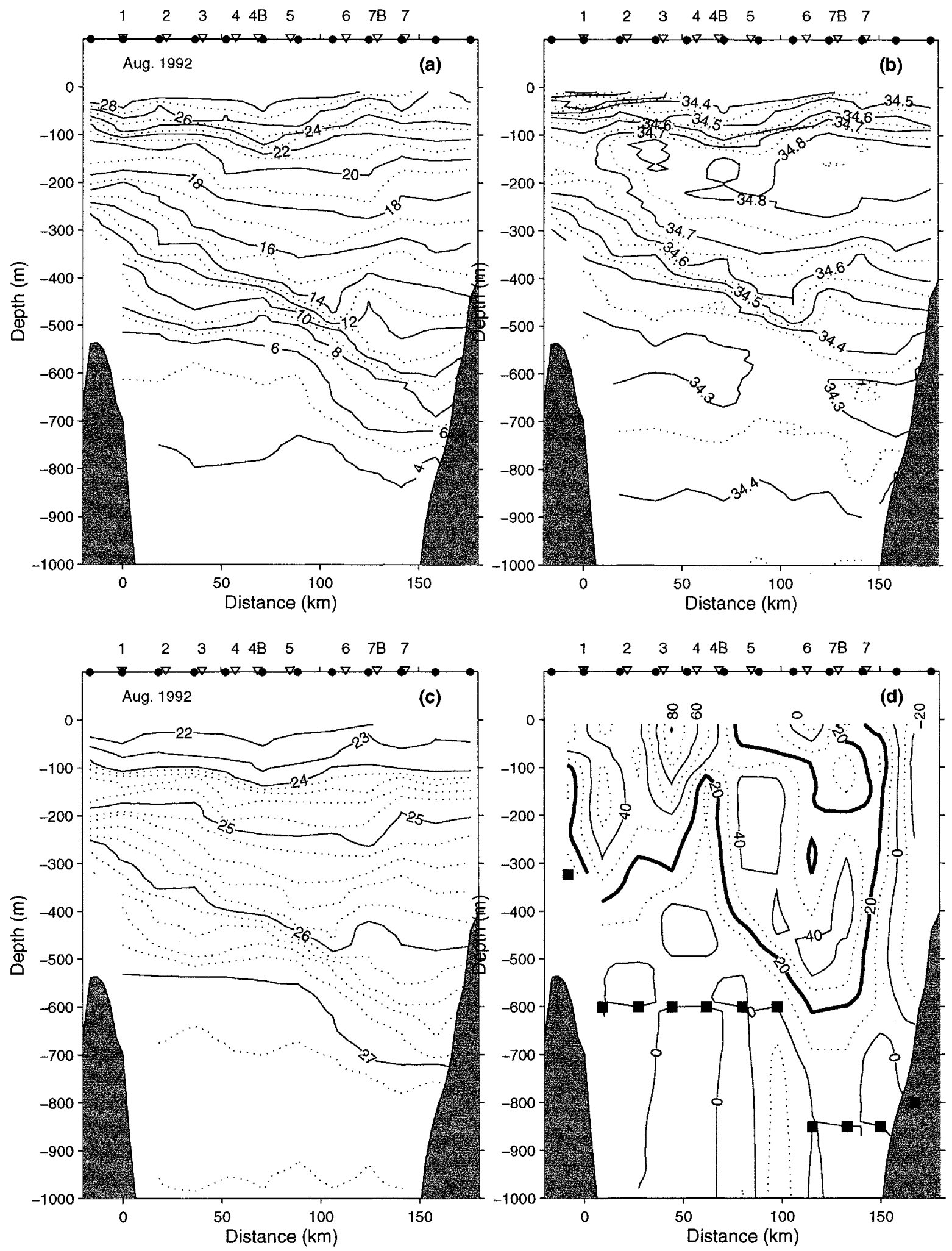

FIG. 4. (a) Temperature, (b) salinity, (c) potential density, and (d) geostrophic current velocity from a CTD section during Aug 1992. The solid circles on the top of the figures indicate the locations of the CTD stations. The solid squares in (d) indicate the reference depths of the velocity calculation; the heavy $20 \mathrm{~cm} \mathrm{~s}^{-1}$ isolines emphasize the subsurface double-core structure. 


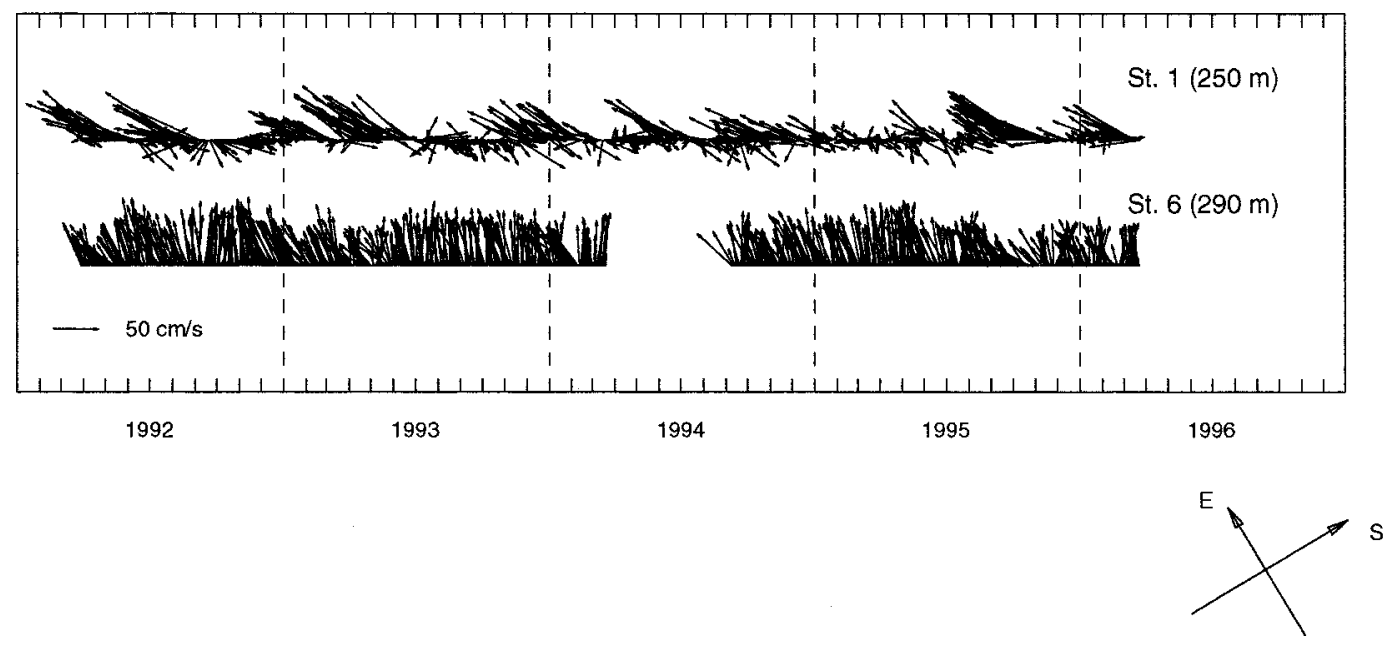

FIG. 5. Time series of current velocities at the 250-m depth level of station 1 and the 290-m depth level of station 6 . The upward direction is toward $121^{\circ}$ (along stream).

agation of $20 \mathrm{~km}$ day $^{-1}$ (James et al. 1999), but variability of this timescale in the strait has not been discussed. Large interannual, as well as semiannual and annual, variations in Kuroshio surface velocity were inferred from the sea level difference across Tokara Strait (Kawabe 1988; Kutsuwada and Morikawa 1996). However, variability of the Kuroshio subsurface structure in this region is poorly known owing to the lack of data.

In the present study, current velocity and temperature observations from the mooring array during 1992-96 (Yamamoto et al. 1998) are used to describe the temporal variability of the Kuroshio in Tokara Strait. We find that the velocity at the northernmost station is a good index that describes the variability of the Kuroshio velocity structure in the strait. Therefore, we further apply this index to the TOPEX/Poseidon (T/P) sea level anomaly to discuss a large-scale context of the variability.

The organization of the present paper is as follows: section 2 introduces the datasets used in the present study. In section 3, a general description of the mooring data is presented. In section 4, variability of mooring data at moorings 1 and 6 is discussed in detail. In section 5 , we analyze the spatial correlations of the Kuroshio variability in terms of short- and long-term timescales, and current velocity composites during the northward and southward axis shifts. Section 6 summarizes the results and discusses the Kuroshio variability in a largescale context.

\section{Data}

The preprocessed hourly current meter and ADCP velocity data and temperature data from the mooring array are provided by the Tokara Strait Mooring Group (Yamamoto et al. 1998). The current meters are equipped with temperature sensors. However, we note that some temperature information was used to estimate the water depths of the instruments on the current meter moorings (Yamamoto et al. 1998). A low-pass filter, optimized to remove the semidiurnal and diurnal tides near Japan, is used to process daily data (Hanawa and Mitsudera 1985). Because most moorings were redeployed every year, small differences occurred in nominal depths. Vertical linear interpolation or extrapolation is used to adjust the depths of the measurements; a cubic spline fit in time is used to fill data gaps of less than two weeks. Some mooring data lack temporal coverage and so are removed from the analysis to avoid biased conclusions. Figure 2 shows depth levels at each mooring station and the time coverage of each depth level; 49 time series are used in the present study. The ADCP data are subsampled vertically every $50 \mathrm{~m}$. The observations are below $200 \mathrm{~m}$ except at the two ADCP moorings, that is, stations 4 and 5. Of the 49 time series, four of them (two at station 1 and two at station 3) have full four year coverage. Further, four time series at stations 2 and 6 have only a half-year gap during MarchSeptember 1994. All the other time series have different time coverages ranging from nine months to less than three years. Therefore, we will discuss the time series of stations 1 and 6 in detail, which indeed represent the variability of the northern and southern cores of the Kuroshio.

Data from a CTD section (Fig. 1) that was surveyed by JAMSTEC in August 1992 were obtained from the Japan Oceanographic Data Center. The section intersects with the mooring array near station 1 and is $22 \mathrm{~km}$ to the east near station 7 . The mooring line direction that connects stations 1 and 7 is $31^{\circ}$ clockwise from north. The positions of other moorings and the CTD stations are projected to this direction.

The 7-km-resolution sea level anomaly data along the T/P orbit are provided by the Collecte Localisation Sat- 

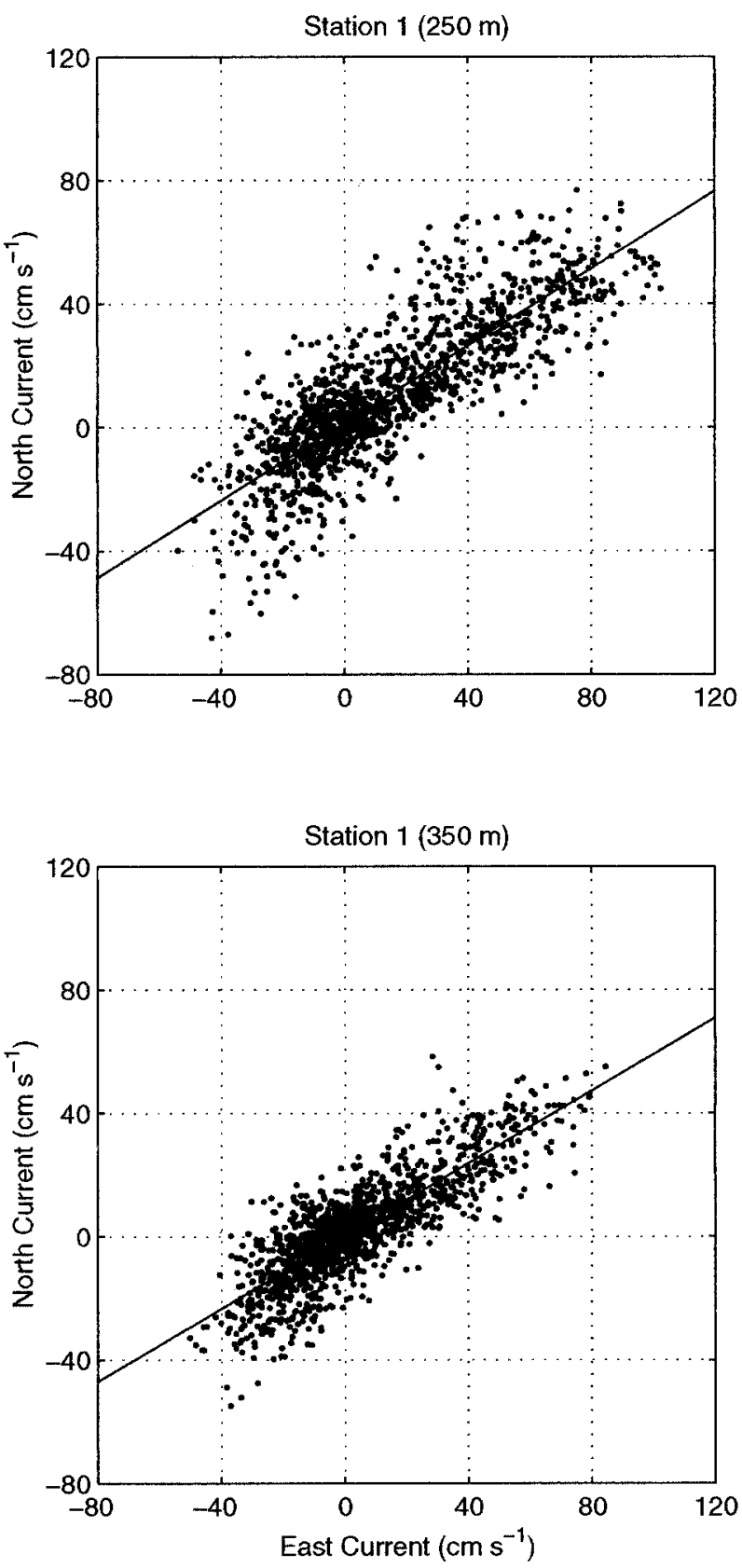

FIG. 6. Scatterplots of current velocities at the 250-m and 350-m depth levels of station 1.

ellites (CLS) Space Oceanography Division, Toulouse, France (AVISO/Altimetry 1996). The mean sea level between cycles 2 and 149 is removed at each grid point. The mean annual cycle with linear trend in horizontal space $\left(26^{\circ}-36^{\circ} \mathrm{N}, 126^{\circ}-142^{\circ} \mathrm{E}\right)$ is removed from the sea level anomaly field. This is consistent in both amplitude and phase with the Southampton Oceanography Centre climatology air-sea heat flux (Josey et al. 1996), when using the linear relationship between surface heat flux and steric sea level anomaly (Stammer 1997). Other
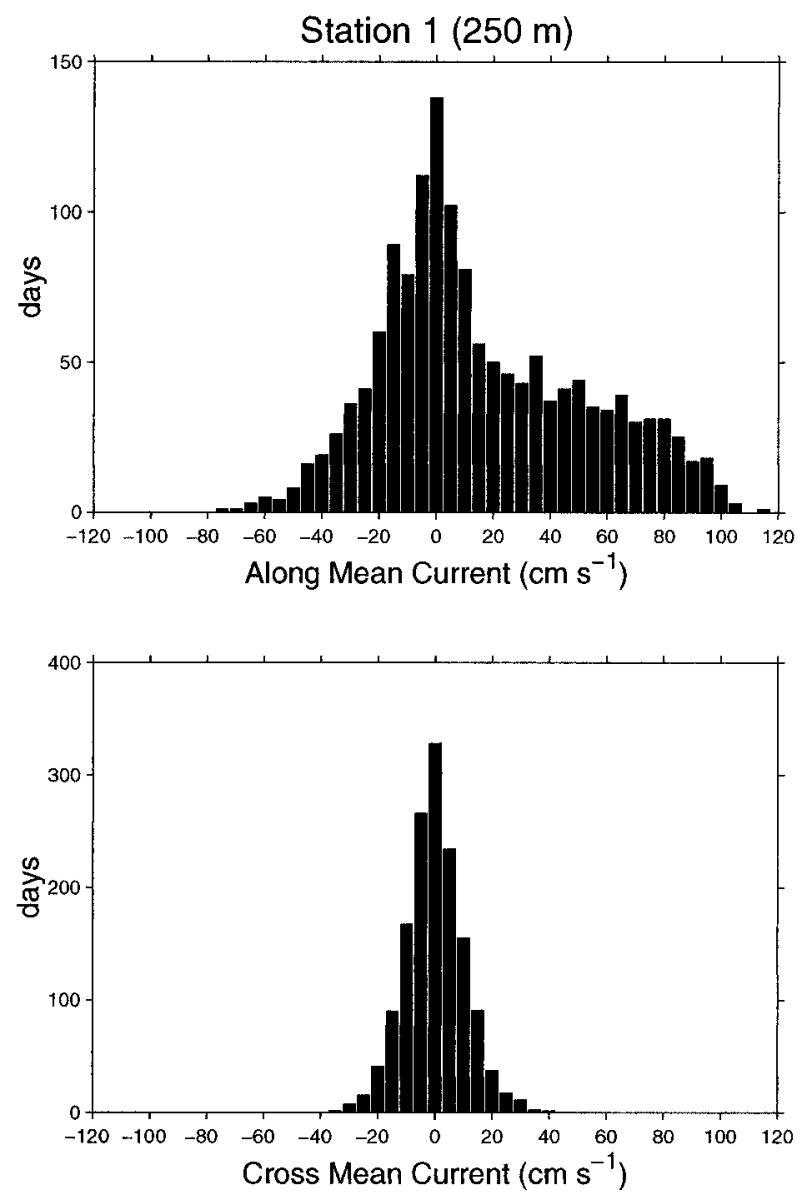

FIG. 7. Histogram of current velocity at the 250-m depth level of station 1 in the along and cross mean current velocity directions.

climatology products (Esbensen and Kushnir 1981; Oberhuber 1988) give consistent phases but smaller amplitudes. A 40-day moving average is used at each grid point to further suppress the tidal signal and other shortterm variability.

\section{General description}

In Tokara Strait, the isobaths are generally in the same direction as the mooring line with increasing water depth to the southeast (Fig. 1). The water depth quickly increases from less than $500 \mathrm{~m}$ in the ECS to more than $4000 \mathrm{~m}$ east of the strait. The water depth along the mooring line ranges from $600 \mathrm{~m}$ at the northernmost station (station 1) to more than $2000 \mathrm{~m}$ at a submarine canyon in the southern portion of the strait. The canyon penetrates from south of Japan to the ECS through the strait between station 5 and Amamioshima Island. North of station 5, the moorings are aligned near the 1000-m isobath. Stations 6 and 7B are right on top of the canyon, a few kilometers west of the mooring line. The southernmost station (station 7) is located at a water depth of about $1700 \mathrm{~m}$. 


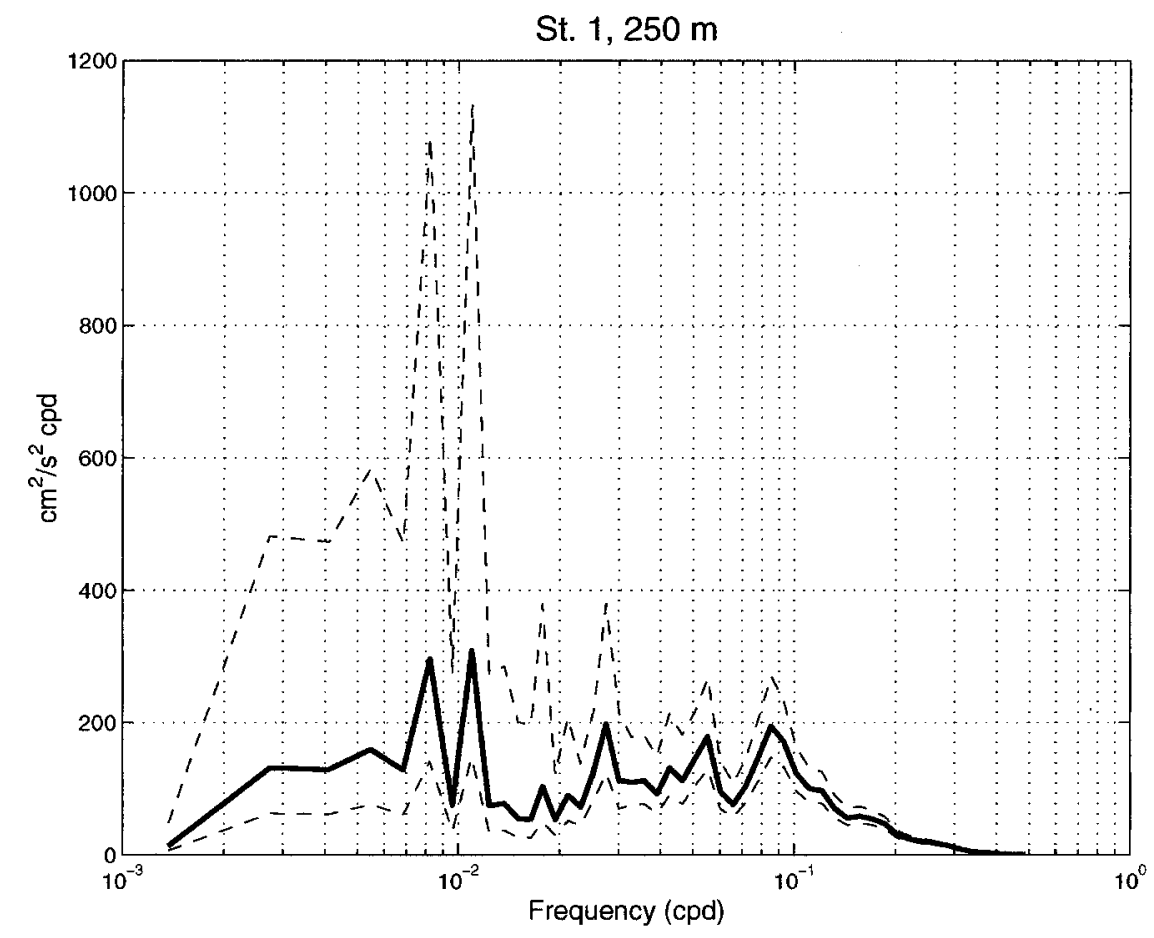

FIG. 8. Energy preserving spectrum of the NE velocity component of station 1. Dashed lines indicate the $90 \%$ confidence intervals.

\section{a. Velocity}

A planar view of the temporal average of all available current velocity data near the 250 -m depth level at each mooring is shown in Fig. 1. The main body of the Kuroshio is located in the southern portion of the strait centered at station 6 on top of the canyon, with a current velocity of $45 \mathrm{~cm} \mathrm{~s}^{-1}$ pointing toward $106^{\circ}$. A second core of the current is found at station 2, with a velocity of $46 \mathrm{~cm} \mathrm{~s}^{-1}$ pointing at $95^{\circ}$. The weaker current velocities at stations 1,4 , and $4 \mathrm{~B}$ tend to point east- to northeastward.

The subsurface double-core structure is more clearly shown in the vertical section of the temporal average alongstream $\left(121^{\circ}\right)$ current velocity (Fig. 3a). The southern core centered at station 6 is broad and penetrates to more than $900 \mathrm{~m}$ south of station 6 , while the northern core centered at station 2 is narrow and relatively shallow. This is consistent with early description of the Kuroshio in Tokara Strait (Nakano et al. 1994). The zerovelocity line is calculated from linear vertical interpolation of the alongstream velocity component at each station. The total volume transport is $23.4 \mathrm{~Sv}$, when we assume no vertical velocity shear from the sea surface to the top depth level at each mooring station. The contribution from the northern core is only $6.7 \mathrm{~Sv}$, while the more broad south core contributes 16.7 Sv. Because there are few data above $200 \mathrm{~m}$ and the dataset is sparse, estimation of the time-varying volume transport is not attempted in the present study.
The presence of the Tokara Islands has been suggested to cause the banded structure of the Kuroshio in the strait (Bingham and Talley 1991), but the islands are about $140 \mathrm{~km}$ upstream from the mooring line. The topography a few miles west of stations 3 and 4 is shallower than $300 \mathrm{~m}$ (Fig. 1), which may act to obstruct the current from flowing in the vicinity of stations 3 and 4 in subsurface layers, and hence should be the main cause of the subsurface double-core structure.

The cross-stream component of the current velocity $\left(31^{\circ}\right)$ is positive above the Kuroshio zero-velocity depth and has peak magnitude of $10-15 \mathrm{~cm} \mathrm{~s}^{-1}$ at the two velocity cores (Fig. 3b). Below 500-600 m between stations 2 and 5 , there is a weak cross-stream undercurrent toward the southwest along isobaths. The southwestward current at station 1 is found at $460 \mathrm{~m}$. A deep undercurrent along the isobaths was previously identified at similar locations (Kawabe 1980; Takematsu et al. 1986) and off Shikoku, Japan (Fukasawa and Teramoto 1986). Existence of a continuous undercurrent along the isobaths in this region was evidenced in numerical models (Hurlburt et al. 1996; Mitsudera et al. 1997). Owing to the existence of the undercurrent, Kawabe (1980) found that the Kuroshio geostrophic volume transport could be overestimated when using 1000 $\mathrm{db}$ as reference depth at a section east of the strait.

Above $500 \mathrm{~m}$, the velocity variances $\left(\overline{u^{\prime 2}+v^{\prime 2}}\right) / 2$ generally decrease to the south, from $350 \mathrm{~cm}^{2} \mathrm{~s}^{-2}$ at the 250 -m depth level of station 1 to about $100 \mathrm{~cm}^{2} \mathrm{~s}^{-2}$ in 

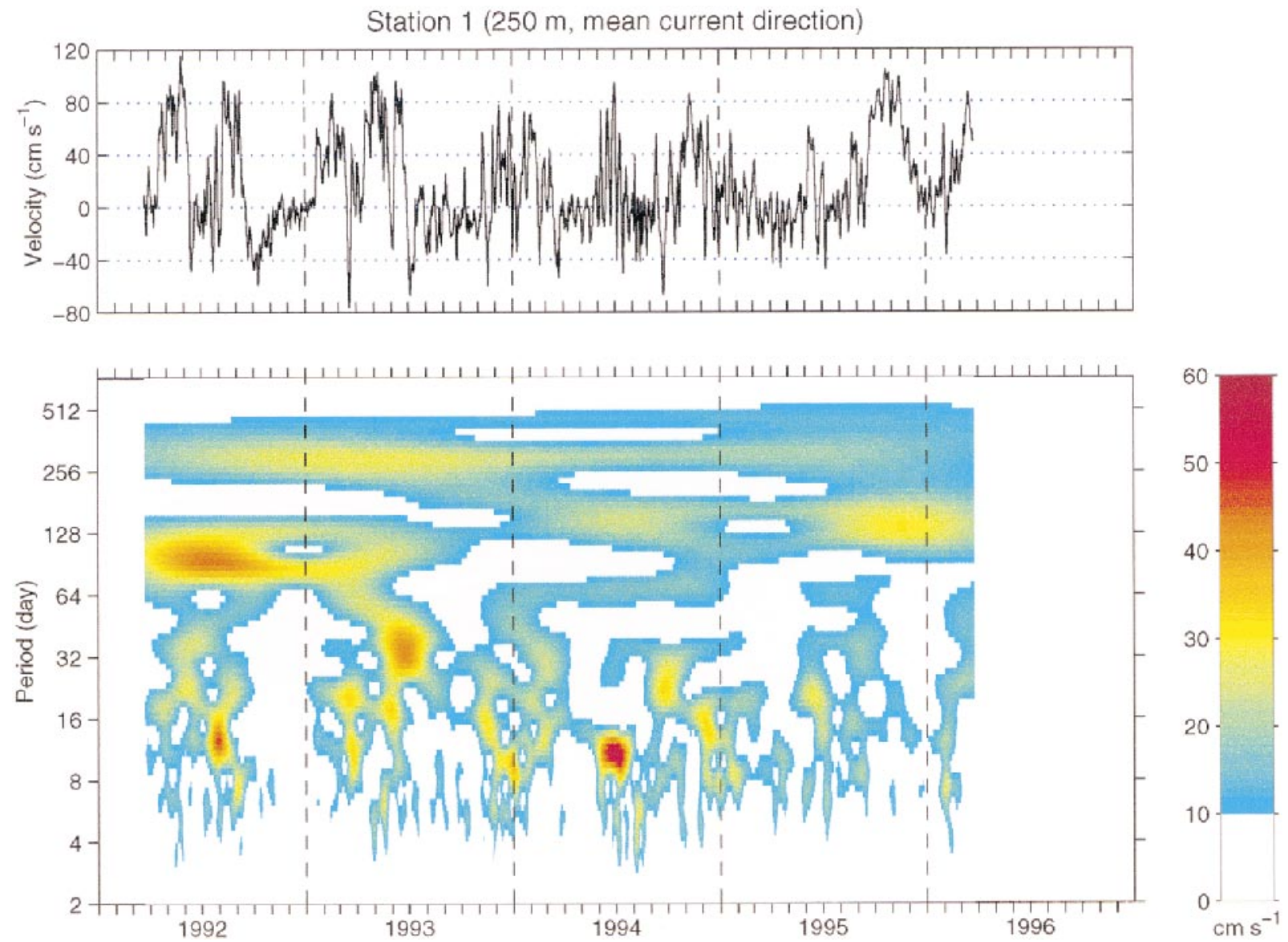

FIG. 9. Time series (upper panel) and amplitude of the wavelet analysis (lower panel) of the NE component (250 m) of station 1.

the southern core, with local minima at stations 3 and 6 (Fig. 3c). Thus, the southern subsurface velocity core is more stable than the northern core. Below $600 \mathrm{~m}$, the velocity variances are mostly below $50 \mathrm{~cm}^{2} \mathrm{~s}^{-2}$, but are slightly larger in the subsurface undercurrent area.

\section{b. Temperature}

The mean temperature ranges from $5^{\circ}$ to $19^{\circ} \mathrm{C}$ between 200 and $800 \mathrm{~m}$ and the isotherms have a general downward inclination toward the southwest (Fig. 3d). Because of the coarse vertical resolution, the interpolated isotherms are almost evenly distributed. Relatively strong horizontal temperature gradients down to $600 \mathrm{~m}$ are found between stations 2 and 3 and between stations 5 and $7 \mathrm{~B}$, consistent with the double-core structure of a geostrophically balanced current. Further, there is a sharp horizontal temperature gradient between stations 6 and 7 below $600 \mathrm{~m}$, consistent with the deep penetrating mean current in the south. We note that some temperature information was used to estimate the water depths of the instruments on the current meter moorings (Yamamoto et al. 1998), hence the spatial variations of temperature may not be fully resolved using the mooring dataset.

\section{c. CTD section}

Temperature structure in the CTD section (Fig. 4a) is similar to the temporal average from the mooring data, but with better vertical resolution. Because of surface heating during summertime, the SST front is not present in the data. We note that both temperature and salinity are stratified in the upper $100 \mathrm{~m}$ (Figs. 4a,b). The temperature is less stratified between the $16^{\circ}$ and $20^{\circ} \mathrm{C}$ isotherms from 300 to $150 \mathrm{~m}$. Sharp vertical temperature gradients are centered near the $12^{\circ} \mathrm{C}$ isotherm, which descends from $300 \mathrm{~m}$ in the north to about $500 \mathrm{~m}$ in the south. The thermocline is partly compensated by the halocline between the salinity maximum water and the North Pacific Intermediate Water (Fig. 4b). The salinity maximum water extends from the south in the depth range of 100-200 m. The intermediate water occupies the range of 500-600 $\mathrm{m}$ in the north and 600-700 $\mathrm{m}$ in the south; thus the southwestward undercurrent is below the intermediate water core. Comparing Figs. 4c and Fig. 3a, the $\sigma_{\theta}=27.0$ depth can be used to represent the lower boundary for the Kuroshio in the north, while the $\sigma_{\theta}=27.2$ isopycnal depth is closer to the Kuroshio lower boundary in the south.

The geostrophic current from the CTD section is cal- 


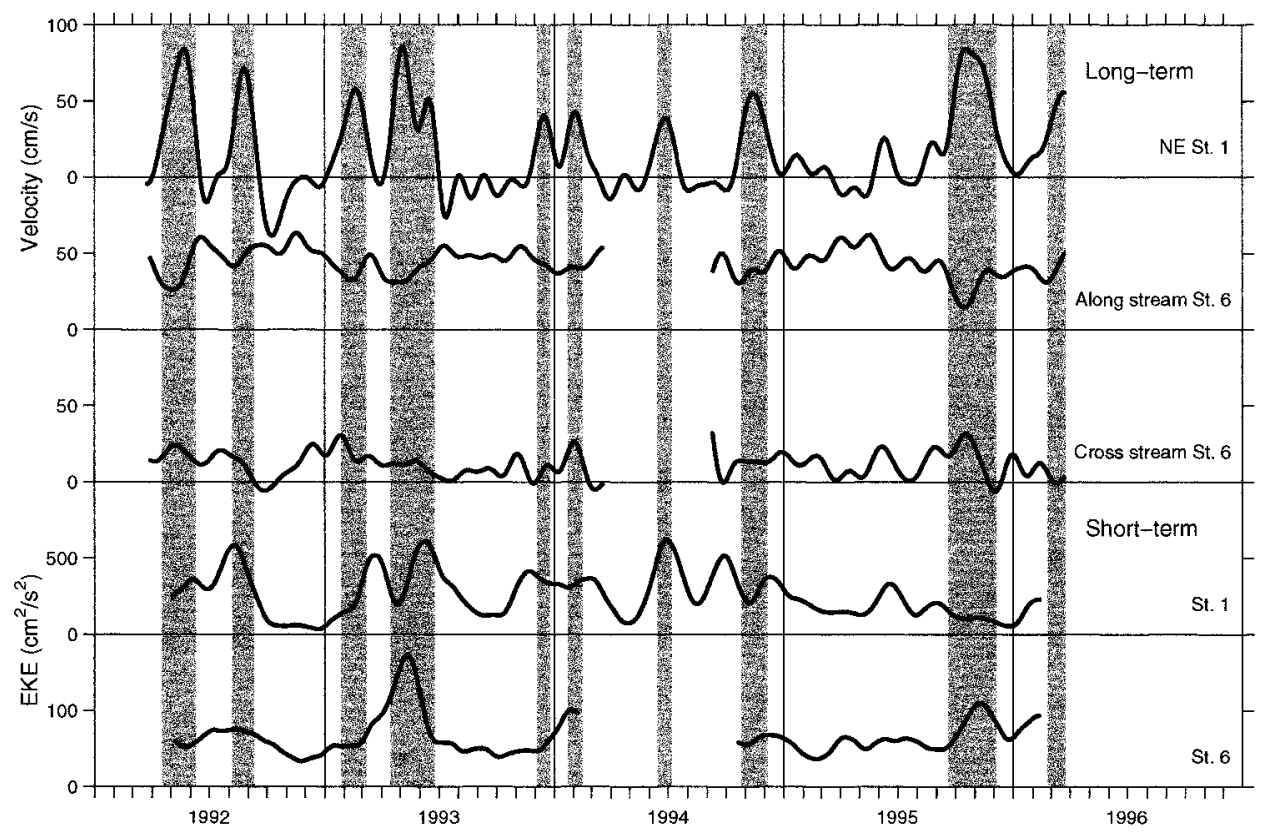

FIG. 10. Long-term time series of the NE component of station 1, the alongstream and cross-stream components at the 290-m depth level of station 6, and the short-term kinetic energy at the 250-m depth level of station 1 and 290-m depth level of station 6 (using a 40-day moving window and further smoothing with a 61-day Hanning filter). The shaded areas indicate periods when the Kuroshio axis shifts northward (determined by the long-term NE component of station 1).

culated with reference to $600 \mathrm{~m}$ north of station 5 and $850 \mathrm{~m}$ in the south (Fig. 4d). Note that selection of the reference layer is based on the mooring data analysis and availability of data. Two near-surface velocity cores are identified near station 1 and between stations 3 and 4 , and two subsurface cores appear near $200 \mathrm{~m}$ between stations 1 and 2 and between stations 5 and 6 . The current velocity between stations 2 and $4 \mathrm{~B}$ has vertical shear in the top $300 \mathrm{~m}$, consistent with mooring data. Westward recirculation of magnitude $20 \mathrm{~cm} \mathrm{~s}^{-1}$ appears south of station 7 .

The relationship between the two subsurface velocity cores and the two surface cores is not conclusive from the present analysis owing to the lack of near-surface measurements, although their coexistence can also be found in other studies (Bingham and Tally 1991; Nakano et al. 1994).

\section{Variability at stations 1 and 6}

The position of station 1 is at $30^{\circ} 2.1^{\prime} \mathrm{N}, 130^{\circ} 56.4^{\prime} \mathrm{E}$ and the isobaths near this station are along the northeastsouthwest direction (Fig. 1). Surface drifters in the Kuroshio sometimes passed through Tokara Strait near station 1 and followed the isobath toward the northeast, though more drifters crossed the strait through the southern portion of the strait as indicated in Fig. 1 of Uchida et al. (1998). The ferry data indicated that the SST frontal fluctuations mostly occurred north of station 4 latitude (Nagata and Takeshita 1985) and affected the sur- face current structure in the northern portion of Tokara Strait (Akiyama et al. 1992). Hence the current velocity variability at station 1 is typical of the Kuroshio frontal variations and axis shift. Station 6 is located at the center of the southern core of the Kuroshio. Its current velocity variability represents that of the southern subsurface core of the Kuroshio.

Figure 5 shows the vector plot of the current velocity at the 250-m depth level of station 1 and at the $290-\mathrm{m}$ depth level of station 6 . The current velocity at station 1 varies most of the time with abrupt northeastward anomalies on timescales from intraseasonal to quasiannual. Shorter timescale variability is also visible. The current velocity at station 6 is more stable and mostly in the direction perpendicular to the strait.

\section{a. Station 1}

From the scatterplots of velocities at depth levels of 250 and $350 \mathrm{~m}$ at station 1 , the current velocities are mostly in the northeast-southwest direction (Fig. 6). The vector-mean velocities are 16 and $3 \mathrm{~cm} \mathrm{~s}^{-1}$ and have directions of $54^{\circ}$ and $59^{\circ}$ for the two layers, respectively. The principal major axis of the current variance is coincident with the mean velocity direction at $250 \mathrm{~m}$, tending to follow the isobath, with a standard deviation of $36 \mathrm{~cm} \mathrm{~s}^{-1}$. The principal major axis of velocity variance at $350 \mathrm{~m}$ is at $58^{\circ}$ with a standard deviation of $25 \mathrm{~cm}$ $\mathrm{s}^{-1}$. The correlation between the along-principal-majoraxis velocities at the two depths is 0.87 , indicating co- 

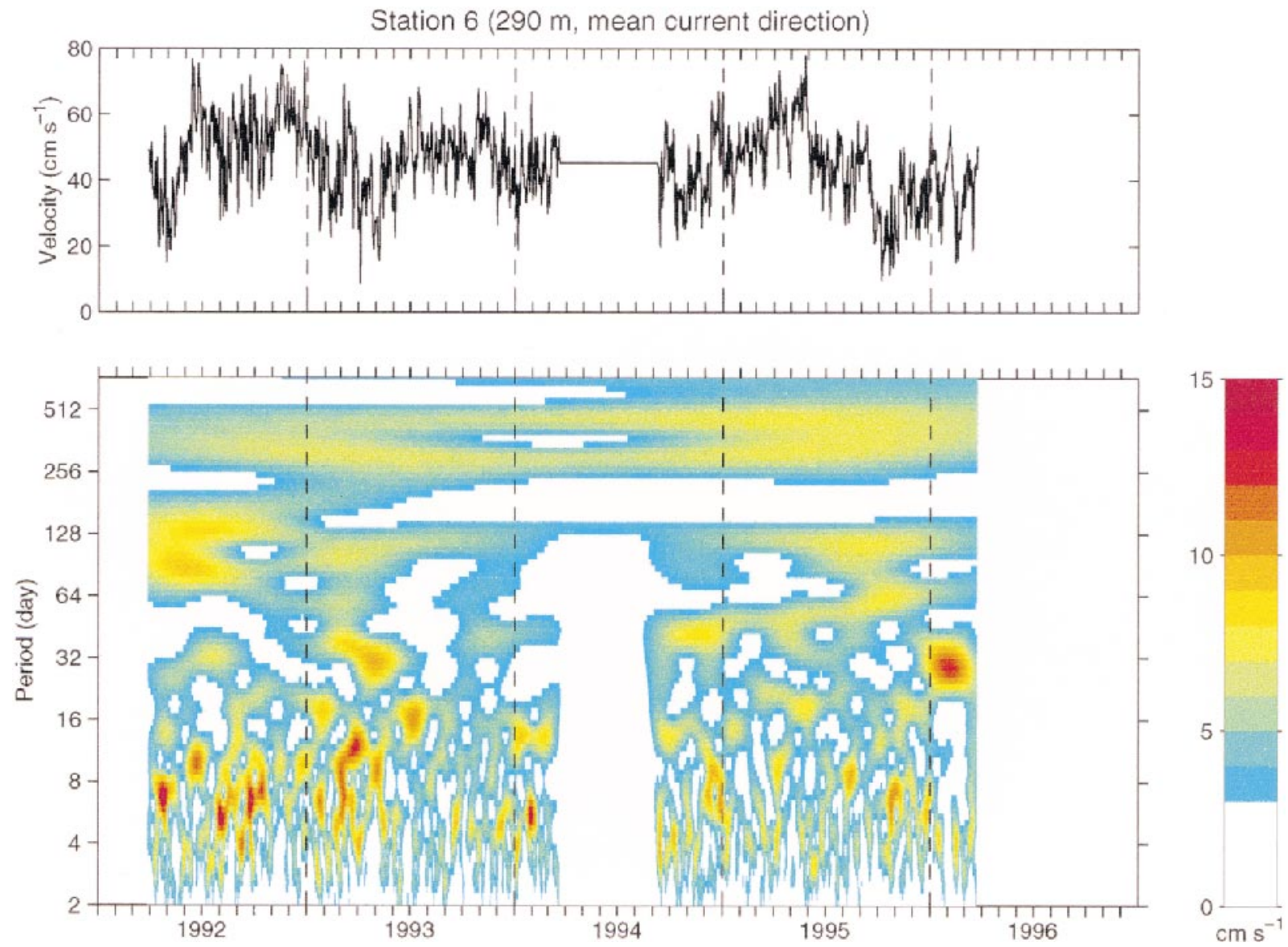

FIG. 11. Time series (upper panel) and amplitude of the wavelet analysis (lower panel) of along-stream component current velocity at the 290-m depth level of station 6. The data gap during Mar-Sep 1994 is padded with zeros in the wavelet analysis of the velocity anomaly.

herent vertical structure of current variability. At 250 $\mathrm{m}$, the histogram of the velocity in the principal minor axis is Gaussian; however the component along the principal major axis is highly skewed, indicating that positive velocity anomalies are stronger than negative velocity anomalies (Fig. 7). Later on, we refer to the current velocity toward $54^{\circ}$ at the 250 -m depth level as the NE component of station 1.

A spectral analysis of the NE component of station 1 is shown in Fig. 8, together with $90 \%$ confidence intervals. There are two prominent peaks in the longterm band, one at three months and the other at four months. There are three other peaks in the short-term band at 10-12 days, 20 days, and one month. It is important to note that there is a spectral gap between the long-term and short-term energy in the period range of 40-80 days. The 10-12 day and 20-day oscillations are likely to be related to the downstream propagating signals in the ECS (Qiu et al. 1990; James et al. 1999).

A wavelet transform (Lau and Weng 1995) of the NE component anomaly of station 1 shows prominent intraannual variability, with a time period in the range between 9 and 11 months (Fig. 9). Also there are clear intraseasonal oscillations, which seem to be locked to a 3-month period before mid-1993 and to a 4-month period after that. Thus, we understand that the 3- and 4-month peaks in the spectral analysis represent oscillations that occurred during different time periods. Interannual changes of dominant frequency were also observed in the SST fluctuations (Nagata and Takeshita 1985). The intraannual to intraseasonal variations at station 1 are weakened from mid-1993 to mid-1995. Coincidentally, the eddy kinetic energy in the Kuroshio and Kuroshio Extension region was also weaker during 1994 than during 1993 and 1995 according to the T/P altimeter data (Adamec 1998).

An elliptic lowpass filter is used to separate longterm variability with time period longer than 40 days and short-term variability with time period shorter than 40 days (Fig. 10). The 40-day selection is based on the spectrum and wavelet analysis, which indicate a spectral separation between 40 to 80 days. The long-term variability has a large horizontal scale as will be shown later. Using the long-term NE component of station 1 as an index of the Kuroshio axis shift, the time periods when positive (negative) anomalies are larger than half 

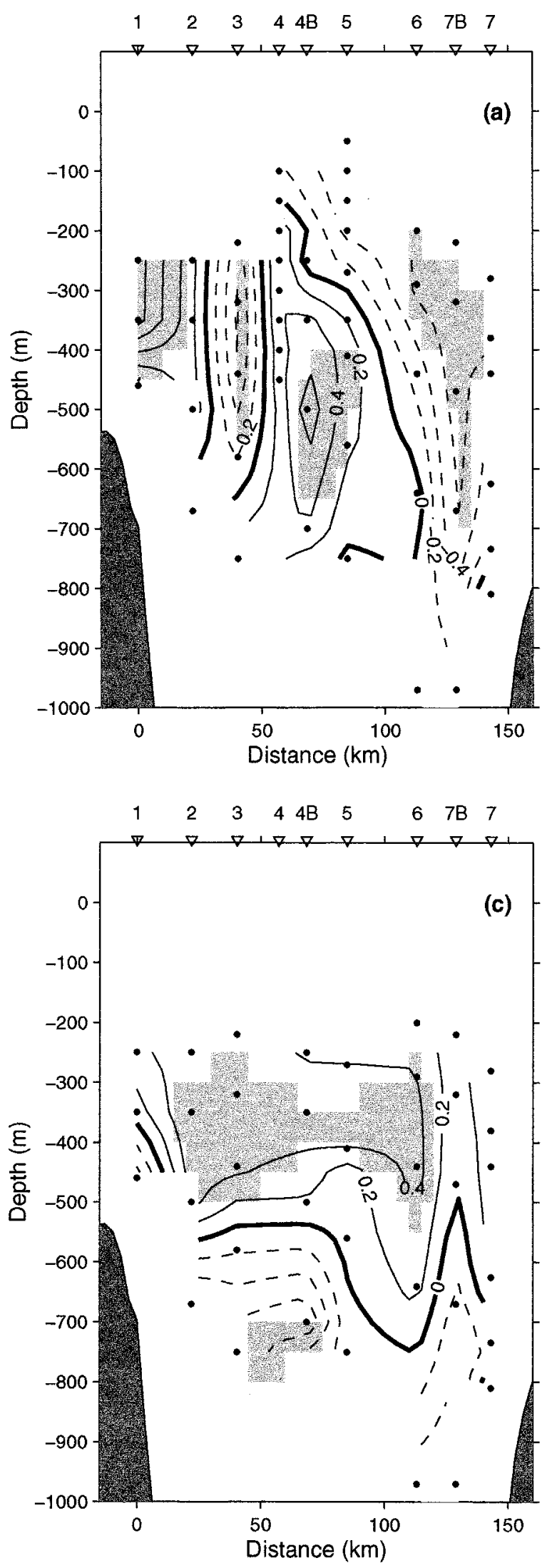

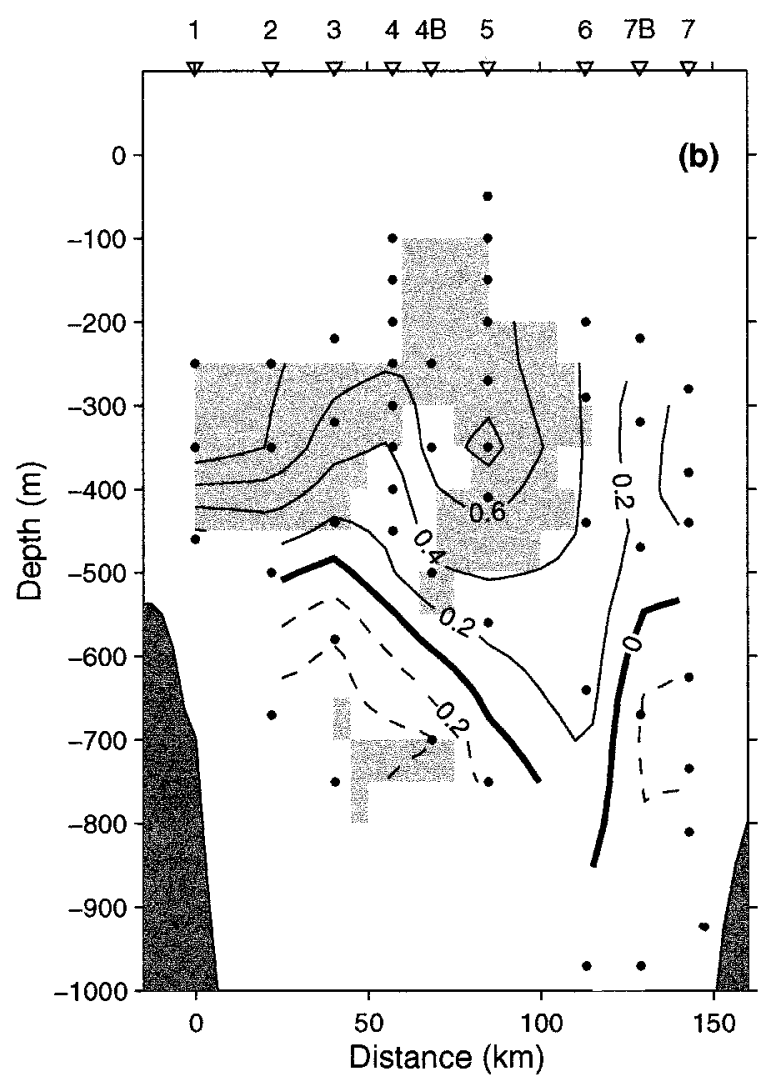

FIG. 12. Correlation between the NE component of station 1 and the (a) alongstream component, (b) cross-stream component of current velocity, and (c) temperature for the long-term variability. The shaded areas indicate that the correlation is above $95 \%$ significance. 

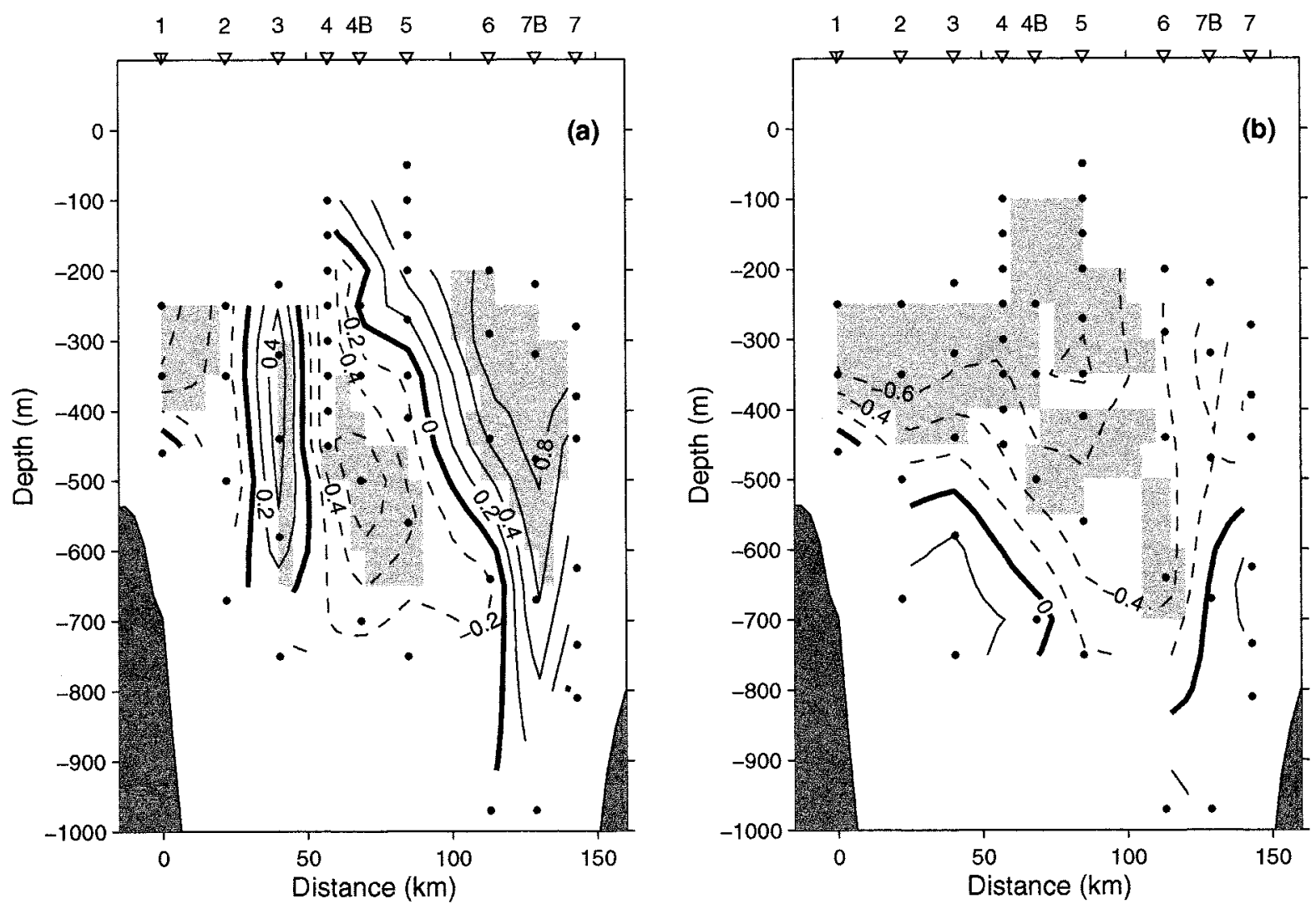

FIG. 13. Correlation between the alongstream velocity component at the 290-m depth level of station 6 and the (a) along-stream component and (b) cross-stream component of current velocity for the long-term variability. The shaded areas indicate that the correlation is above $95 \%$ significance.

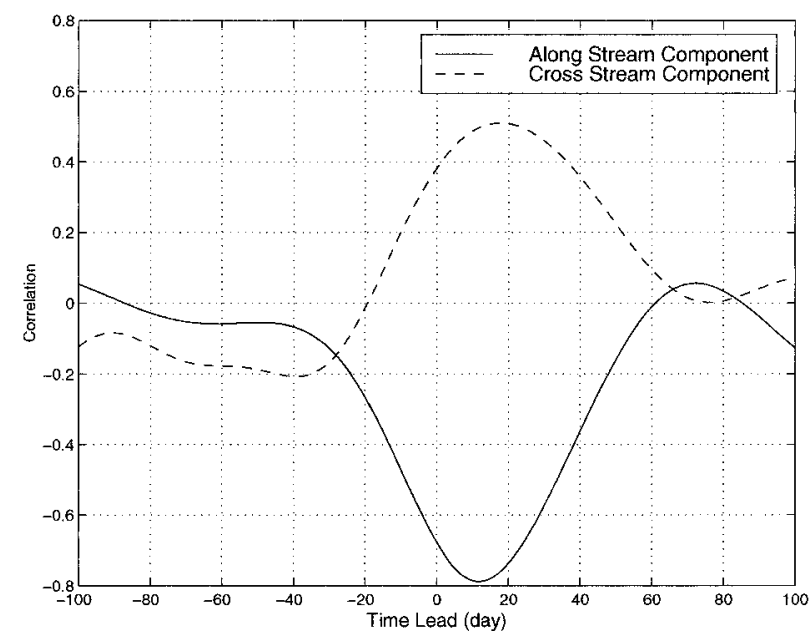

FIG. 14. Time lag correlation between the NE component of station 1 and the along-stream and cross-stream components of current velocity at the 290-m depth level of station 6 for the long-term variability. Positive values denote station 6 leads station 1 . of its standard deviation are regarded as the northern (southern) shifts of the current axis (Figs. 2 and 10). The northward shift of the current axis typically lasts for one to two months and the transition between positive anomaly and normal condition typically lasts for one month.

The wavelet analysis shows strong short-term oscillations with periods ranging from 10 days to one month at station 1 (Fig. 9). The durations of the short-term oscillations usually last no longer than two to three months. Oscillations with different frequencies tend to occur during different time periods. Sometimes, the short-term velocity anomalies have larger magnitude than the long-term variability, especially when the longterm variability is weak during mid-1993 to mid-1995 (Fig. 9). The occurrences of strong short-term oscillations seem to be associated with positive anomalies in the long-term variations (Fig. 10). There is, however, no strong short-term activity associated with the longterm positive anomaly during October-November 1995.

\section{b. Station 6}

At station 6, the vector-mean current velocity at the $290-m$ depth level has direction of $106^{\circ}$ and magnitude 


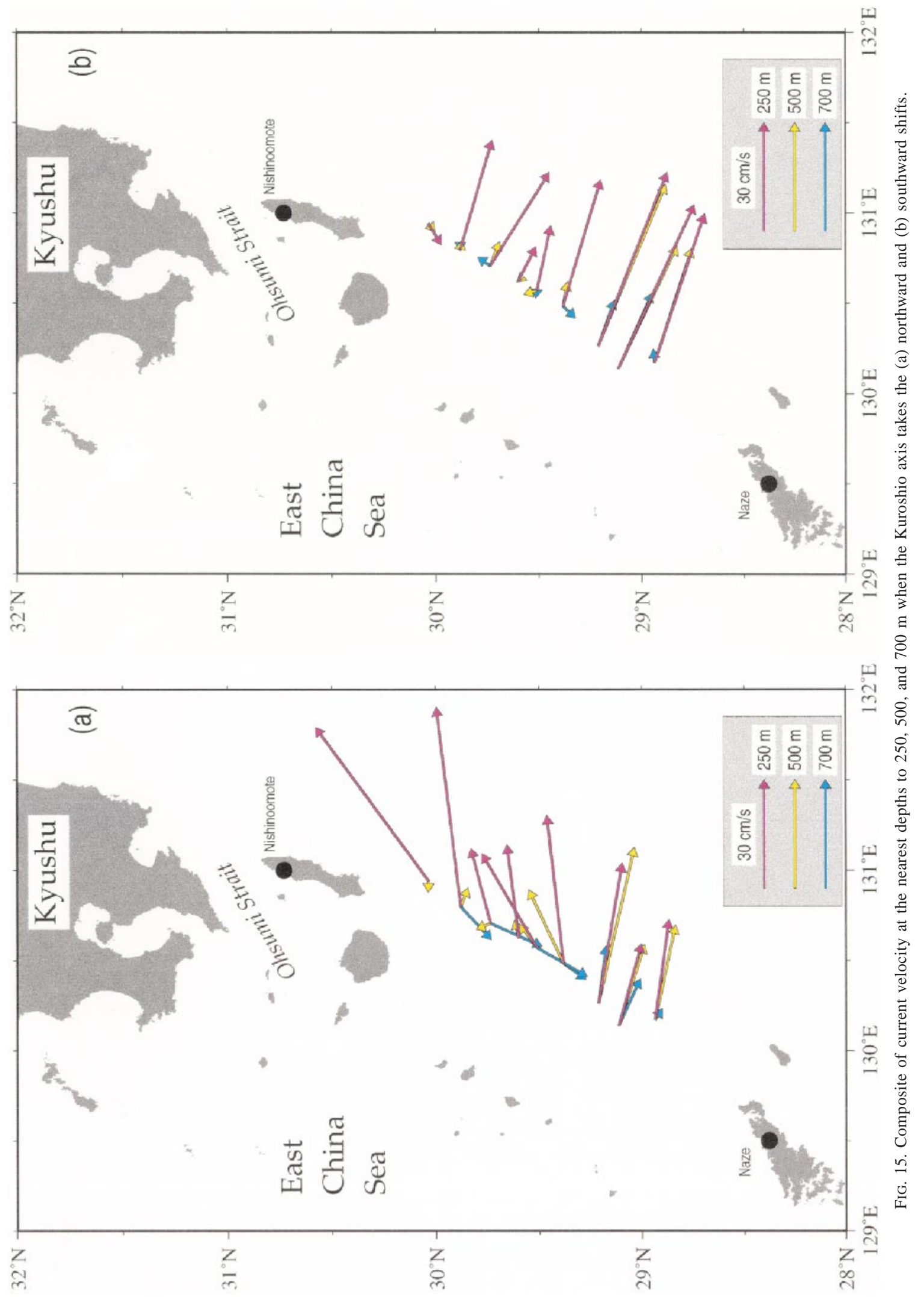



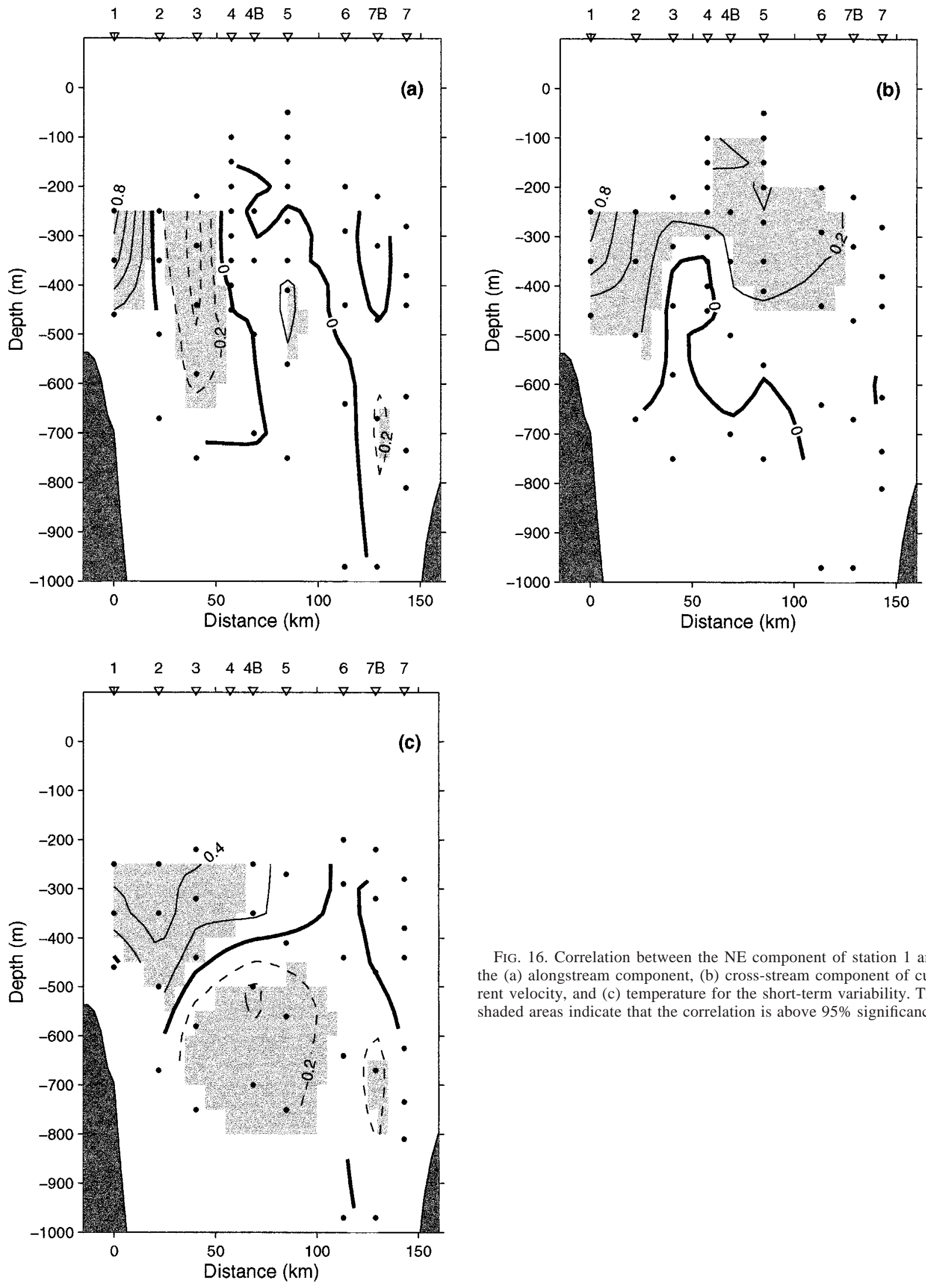

FIG. 16. Correlation between the NE component of station 1 and the (a) alongstream component, (b) cross-stream component of current velocity, and (c) temperature for the short-term variability. The shaded areas indicate that the correlation is above $95 \%$ significance. 


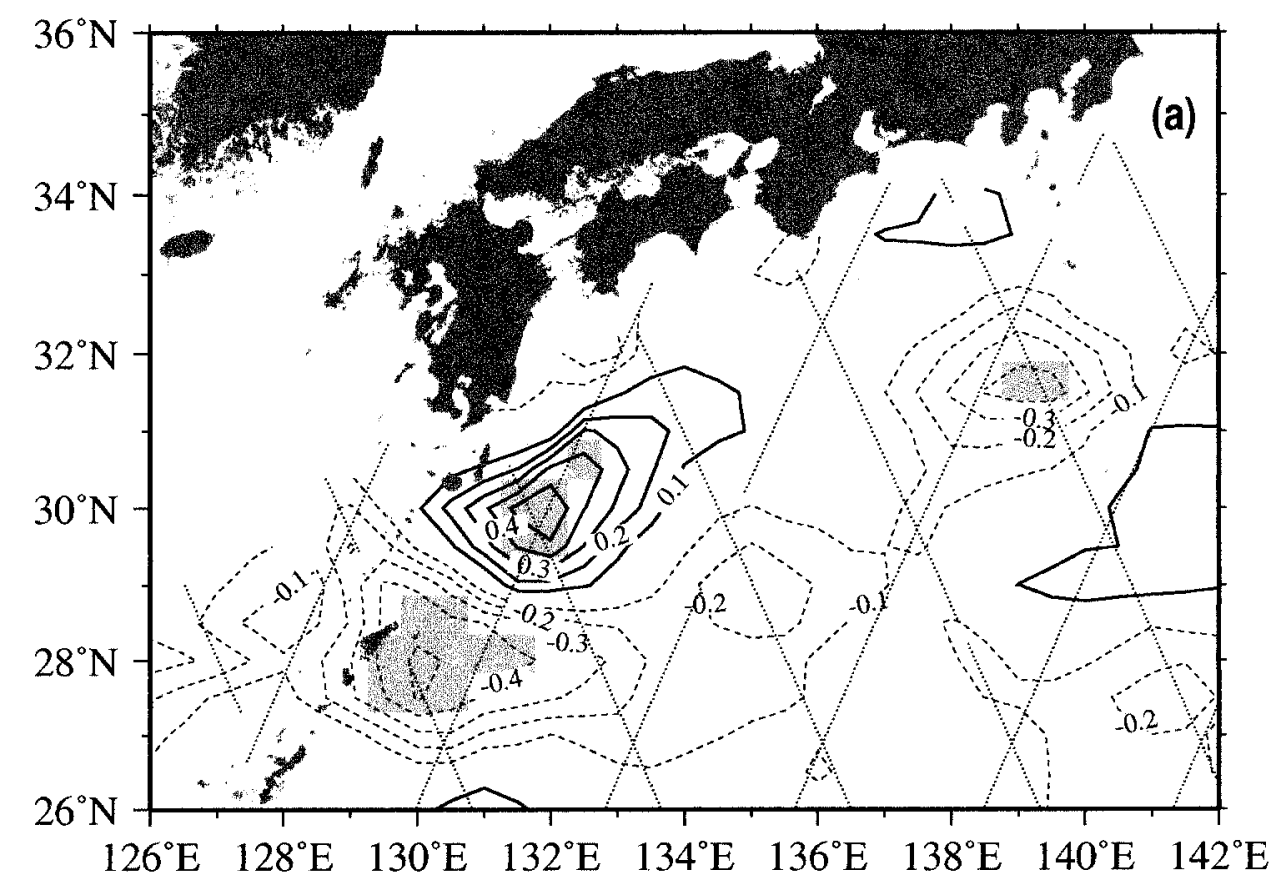

FIG. 17. (a) Correlation between the long-term NE component of station 1 and the T/P sea level anomaly, and composite of the T/P sea level anomaly when the Kuroshio axis shifts (b) northward and (c) southward. The light-shaded areas in (a) indicate the correlations are above $95 \%$ significant level. The overlaid vectors in (b) and (c) are velocity composites at $250 \mathrm{~m}$. Light dots indicate the T/P ground tracks.

of $45 \mathrm{~cm} \mathrm{~s}^{-1}$ (Fig. 1). The principal major axis of the current variance has a $53^{\circ}$ angle relative to the mean velocity direction, with standard deviations at the major and minor axes of 14 and $10 \mathrm{~cm} \mathrm{~s}^{-1}$, respectively (showing that there is a negative correlation between the alongstream and cross-stream components).

A wavelet transform is carried out for the current velocity anomaly in the alongstream direction at $290 \mathrm{~m}$ (Fig. 11). The quasi-annual signal is obscure owing to the data gap, while there are more dominant 4-month oscillations. The long-term variations are out of phase with those at station 1 during most of the time, indicating that the current velocity at station 6 decreases when the current axis shifts northward (Fig. 10). The cross-stream component tends to be out of phase with the alongstream component in the long-term variability. The short-term energy at station 6 is much weaker than at station 1 and has several high energy periods corresponding to positive anomalies in the long-term $\mathrm{NE}$ component of station 1 (Fig. 10).

\section{Spatial structure of the variability}

To obtain the spatial structure of the current variability, we calculate correlations between velocity/temperature and the NE component of station 1 (see section $4 \mathrm{a}$ for definition) or the alongstream $\left(121^{\circ}\right)$ component at the 290-m depth level of station 6. The significance test (Sachs 1978) is based on the degrees of freedom calculated with the cross products of the autocorrelation functions (Fraedrich et al. 1995).

\section{a. Long-term variability ( $>40$ days)}

The correlation between the NE component of station 1 and the alongstream component shows a striking twofold banded structure in the long-term variability (Fig. $12 \mathrm{a})$. Correlation with station $7 \mathrm{~B}$ is negative and high (the correlations are stronger than -0.6 from $250 \mathrm{~m}$ down to $600 \mathrm{~m}$ ). The correlations at stations $4 \mathrm{~B}$ and 5 are mostly positive and significant below $400 \mathrm{~m}$. Further, there is significant negative correlation at station 3. It is noteworthy that this banded structure is due to the north-south shift of the double-core structure of the Kuroshio. Therefore, the signs of the velocity gradient in Fig. 3a correspond to this banded structure.

There is no banded structure in the cross-stream component and temperature correlations (Figs. 12b,c). The correlations are significantly positive in the upper layer north of station 6 . This implies that the veering of the Kuroshio axis direction is a dominant signal in the crossstream component variability. There are negative correlations in lower layers below $600 \mathrm{~m}$ at stations 2, 3, and 4 in both cross-stream component and temperature correlations. This indicates that there exists a stronger 

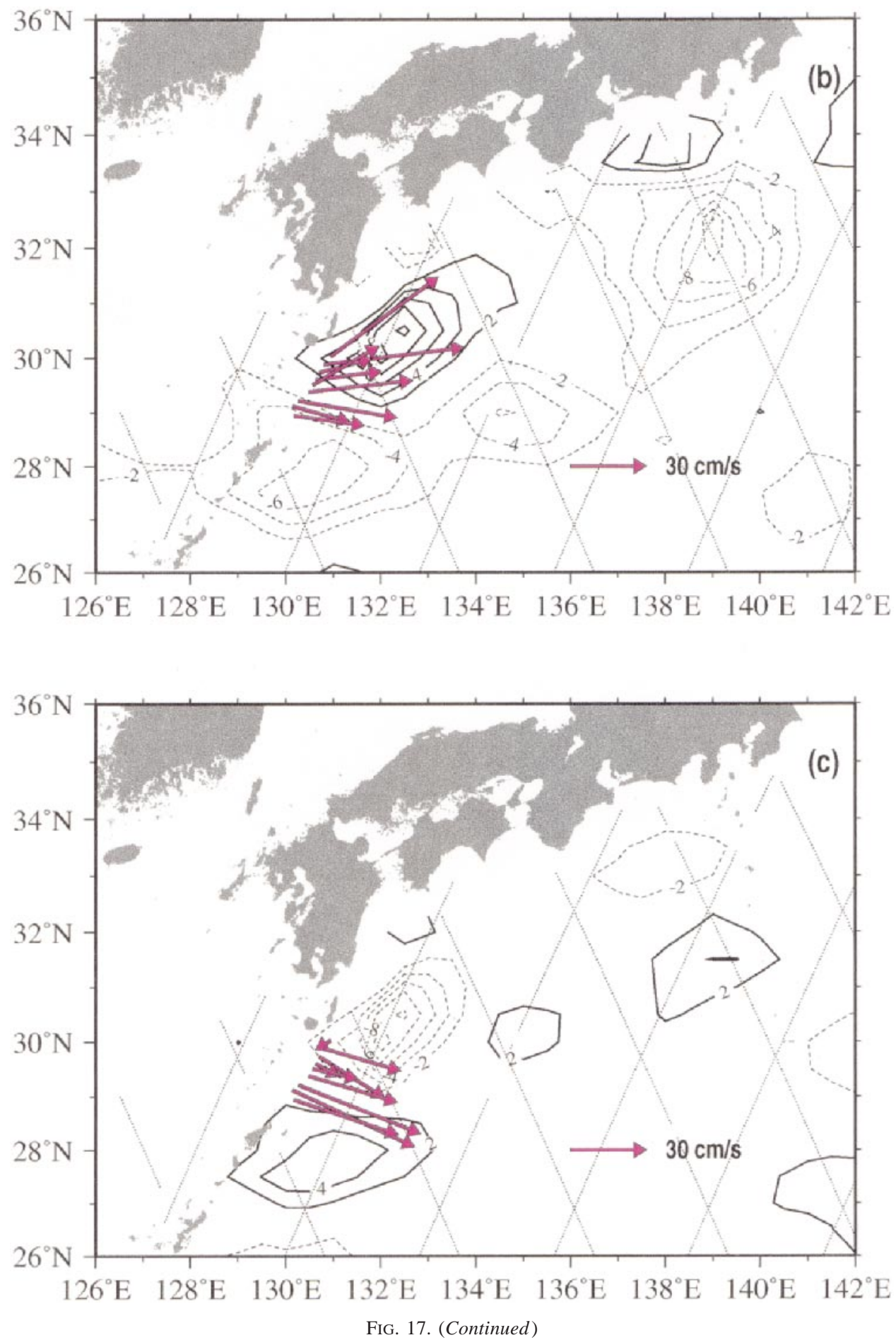

cross-stream undercurrent when the Kuroshio axis shifts northward.

The correlations with the alongstream current velocity component at the 290-m depth level of station 6 are very similar to the results from station 1 (Fig. 13). Note that the alongstream component at station 6 is almost out of phase with station $1 \mathrm{NE}$ component variability so that all the correlations change signs. The crossstream undercurrent is less correlated with the variability at station 6 .

For the long-term variability, the alongstream component of current at the 290-m depth level of station 6 leads the variability of NE component of station 1 by about 12 days with a correlation of -0.79 (Fig. 14). 
The cross-stream component of current at station 6 leads the station 1 variations by 18 days with a correlation of 0.51 . Thus, both the weakening and northward veering of current in the southern core lead the strengthening of current in the northern portion of the strait, and vice versa. The reason for this time lag relationship needs further analysis.

In summary, the velocity variations longer than 40day period have a large spatial scale whose pattern is consistent with the double-core structure of the Kuroshio. This in turn implies that the NE component of station 1 can be used as an index of the long-term current structure variability in the strait.

\section{b. Composite of current structures}

Figure 15 displays composite current structures during the northern and southern shifts of the Kuroshio axis in terms of the above index. Comparing with the averaged current structure in Fig. 1, the current at $250 \mathrm{~m}$ backs cyclonically at most locations during the northward shift (Fig. 15a). The current at stations 1 and 2 is strengthened and the velocity at station 1 points toward northeast with magnitude $57 \mathrm{~cm} \mathrm{~s}^{-1}$. The velocity of the southern core (at stations 6, 7B, and 7) decreases. The double-core structure still remains.

The situation reverses when the Kuroshio shifts southward (Fig. 15b). The maximum velocity is located near station 6 and the current points in the direction perpendicular to the strait at $250 \mathrm{~m}$. The current velocity at station 1 is slightly reversed. This is an indication of a cyclonic eddy east of the strait; this feature will be further discussed from a large-scale context. The northern velocity core is located between stations 2 and 3 .

At 500-m depth, velocity south of station 6 follows the upper-layer velocity variation. On the other hand, the velocity and its variability are small north of station 4B. Velocity at station 5 is variable; it is strong during the northward shift, and vice versa. This feature is consistent with the north-south shift of the southern core.

At $700 \mathrm{~m}$, the southwestward cross-stream undercurrent velocity is larger than $10 \mathrm{~cm} \mathrm{~s}^{-1}$ north of station 5 during the northward axis shift. In contrast, it almost disappears during the southward shift period. This is somewhat counterintuitive. One possible explanation is that the southward shift of the Kuroshio in the surface layer stretches the deep-layer water column in a twolayer model. Hence northward motion is induced in the deep layer in order to conserve potential vorticity and blocks the undercurrent.

\section{c. Short-term variability ( $<40$ days)}

The structure of the current velocity variances in the short-term variability (not shown) is very similar to Fig. $3 \mathrm{c}$, so that high energy exists only near the northern front. The zero-lag correlations are taken between the short-term NE component of station 1 and other moor- ing velocities (Figs. 16a,b). The short-term variability of station 1 has significant alongstream component correlations only with the northernmost stations, positive at station 1 and negative at station 3. Correlations with the cross-stream component are only larger than 0.4 at stations 1 and 2 . Thus, the short-term variability at station 1 is related to frontal activity near the northern boundary of the subsurface Kuroshio current. This is consistent with the ferry boat SST observations (Nagata and Takeshita 1985).

Figure $16 \mathrm{c}$ shows that the correlations between the station 1 velocity and temperature time series are significantly nonzero $(>0.3)$ from station 1 to station 3 in the upper $400 \mathrm{~m}$. Negative correlations can be found in deep layers from station 3 to station 5. This may be related to thermocline variations associated with the frontal activity of the Kuroshio.

\section{Summary and discussion}

Four years of mooring array observation data are used to analyze the characteristics and temporal variability of the Kuroshio in Tokara Strait. The Kuroshio shows a subsurface double-core structure in the strait, most probably due to topographic blockage. The northern core is shallower than $500 \mathrm{~m}$ and the southern core penetrates deeper than $600 \mathrm{~m}$. The lower boundary of the Kuroshio ranges between 400 and $600 \mathrm{~m}$ in the northern portion of the strait and is about $900 \mathrm{~m}$ in the south.

The Kuroshio variability is divided into a long-term band with time periods longer than 40 days and a shortterm band with time periods shorter than 40 days according to the spectrum and wavelet analysis. The shortterm variability has high kinetic energy near the northern front of the Kuroshio and has confined cross-stream spatial scale, indicating frontal variability. The longterm variability is dominated by intraannual to intraseasonal timescales and has a correlated structure across the whole current, indicating north-south axis shift of the Kuroshio current.

The Kuroshio axis shift can be indexed with the northeastward velocity at the northernmost station (the NE component of station 1). The typical timescale when the Kuroshio shifts northward is one to two months and the transition is typically within one month. When the Kuroshio axis shifts southward, the mean current points nearly perpendicular to the strait and the current at the northernmost station slightly reverses; on the other hand, when the Kuroshio axis shifts northward, the mean current backs toward the east, the southern core shifts northward, and the current at the northernmost station is strong and points to the northeast.

There is a southwestward cross-stream undercurrent below $600 \mathrm{~m}$ flowing along the isobaths in the northern portion of Tokara Strait. The undercurrent becomes stronger (more than $10 \mathrm{~cm} \mathrm{~s}^{-1}$ ) when the Kuroshio axis shifts northward. 
As demonstrated in sections $5 \mathrm{a}$ and $5 \mathrm{~b}$, the low-frequency (long-term) Kuroshio variability in Tokara Strait has a well-defined structure, and the NE component of station 1 can be used as an index of this low-frequency variability. A natural question is how this variability is related to larger-scale circulation.

The correlations between the Kuroshio index and the T/P sea level anomaly show a dipole structure east of the strait with a positive north (negative south) center east of Tanegashima (Amamioshima) Island, where the correlation magnitudes are well above 0.5 and are $95 \%$ significant (Fig. 17a). Further, there is a high negative correlation region (magnitude $>0.4$ ) off the southern coast of Japan, centered at $32^{\circ} \mathrm{N}, 139^{\circ} \mathrm{E}$ where the $\mathrm{Ku}-$ roshio shifts southward during its meander-type path; note that although the stationary large meander did not occur during the observation period, there were several transitions from a straight path to a meander-type path that lasted for a few months (short-term meander). This correlation implies that the Kuroshio tends to take the short-term meander path when its axis shifts northward in Tokara Strait.

The relationships are clearly seen in composites of the sea level anomaly in Figs. 17b,c, where the composites are calculated in terms of the Kuroshio index. The velocity composites of $250 \mathrm{~m}$ are also superimposed in the figures. When the Kuroshio axis shifts northward, there is a positive sea level anomaly off Kyushu with a maximum anomaly of more than $10 \mathrm{~cm}$. The current at the northern core is stronger than average corresponding to this sea level anomaly in a geostrophic sense. East of Amamioshima Island, there is a negative anomaly, consistent with the weaker southern core current. When the Kuroshio axis shifts southward, the situation east of the strait reverses, with a negative anomaly in the north and a positive anomaly in the south. A velocity composite at $250 \mathrm{~m}$ follows the contours of the negative anomaly off Kyushu, indicating formation of a meander there.

During the northward shift in the strait, there is a depression of sea level $(\approx 10 \mathrm{~cm})$ centered at $32^{\circ} \mathrm{N}$, $139^{\circ} \mathrm{E}$. On the other hand, there is almost no sea level signal in this region for the reversed case. This is a tendency similar to what Kawabe (1995) found from coastal sea level data; he used three sea level stations across Tokara Strait to construct a "Kuroshio Position Index" (KPI), whereas the sea level difference between Uragami and Kushimoto in the Kii Peninsula was used for an index of the large meander. It should be noted, however, that his finding is mainly for stationary large meander cases where the timescale is interannual to decadal, whereas here we are concerned with the shortterm meander variability that has intraseasonal timescale.

From the T/P data, some of the negative anomalies east of the strait propagate downstream (not shown), causing the near 100-day excursion of the Kuroshio axis along the Affiliated Surveys of the Kuroshio off Ash- izuri-misaki (ASUKA) line about $250 \mathrm{~km}$ east of Tokara Strait (Wimbush et al. 1998). This issue will be addressed in a separate study. Further, 100-day variations were found off Taiwan about $1000 \mathrm{~km}$ upstream from the strait, associated with fluctuations of the subtropical front (Qiu 1999; Lee et al. 1999, manuscript submitted to J. Phys. Oceanogr.). The relation between these fluctuations and the intraseasonal variability in the strait still needs further analysis.

Acknowledgments. We would like to thank Bo Qiu, Takuji Waseda, and two anonymous reviewers for their critical reading of the manuscript and invaluable comments. The KER field experiment at Toara Strait was conducted as an interagency effort involving the Japan Meteorological Agency, Meteorological Research Institute, Maritime Safety Agency, and Japan Marine Science and Technology Center, promoted by the Science and Technology Agency, Japan. The Kagoshima University also participated in this experiment. Diane Henderson helped with the text. HM and MF are grateful to the support from the Frontier Research System for Global Change. The International Pacific Research Center is partly sponsored by the Frontier Research System for Global Change.

\section{REFERENCES}

Adamec, D., 1998: Modulation of the seasonal signal of the Kuroshio extension during 1994 from satellite data. J. Geophys. Res., 103, $10209-10222$.

Akiyama, H., Y. Ohno, and S. Saitoh, 1992: Kuroshio warm filament passing around the Tokara Strait (in Japanese with English abstract). Umi to Sora, 68, 99-112.

AVISO/Altimetry, 1996: AVISO (Archive, Validation and Interpretation of Satellite Oceanographic data) user handbook for sea level anomaly altimeter products. Edition 2.0. AVI-NT-011-312CN, 26 pp. [Available from CLS, Space Oceanography Division, 8-10, rue Hermès, 31526 Ramonville Saint-Agne, France.]

Bingham, F. M., and L. D. Talley, 1991: Estimates of Kuroshio transport using an inverse technique. Deep-Sea Res., 38, S21-S43.

Chao, S.-Y., 1984: Bimodality of the Kuroshio. J. Phys. Oceanogr., 14, 92-103.

Esbensen, S. K., and Y. Kushnir, 1981: The heat budget of the global ocean: An atlas based on estimates from surface marine observations. Climate Research Institute, Oregon State University Tech. Rep. 29, 27 pp. [Available from Oregon State University, Corvallis, OR 97331.]

Fraedrich, K., C. Ziehmann, and F. Sielmann, 1995: Estimates of spatial degrees of freedom. J. Climate, 8, 361-369.

Fukasawa, M., and T. Teramoto, 1986: Characteristics of deep currents off Cape Shiono-mosadi before and after formation of the large meader of the Kuroshio in 1981. J. Oceanogr. Soc. Japan, 42, 53-68.

Hanawa, K., and H. Mitsudera, 1985. On daily average of oceanographic data. Coastal Oceanogr. Bull., 23, 79-87.

Hurlburt, H., A. Wallcraft, W. Schmitz, P. Hogan, and E. Metzger, 1996: Dynamics of the Kuroshio/Oyashio current system using eddy-resolving models of the North Pacific Ocean. J. Geophys. Res., 101, 941-976.

James, C., M. Wimbush, and H. Ichikawa, 1999: Kuroshio meanders in the East China Sea. J. Phys. Oceanogr., 29, 259-272.

Josey, S. A., E. C. Kent, D. Oakley, and P. K. Taylor, 1996: A new 
global air-sea heat and momentum flux climatology. Int. WOCE Newslett., 24, 3-5.

Kawabe, M., 1980: Sea level variations around the Nansei Islands and the large meander in the Kuroshio south of central Japan. J. Oceanogr. Soc. Japan, 36, 227-235.

— 1988: Variability of Kuroshio velocity assessed from the sealevel difference between Naze and Nishinoomote. J. Oceanogr. Soc. Japan, 44, 293-304.

- , 1995: Variations of current path, velocity, and volume transport of the Kuroshio in relation with the large meander. J. Phys. Oceanogr., 25, 3103-3117.

Kutsuwada, K., and Y. Morikawa, 1996: Interannual variability of the Kuroshio path/transport south of Japan using coastal sealevel. Tokai University Rep., 41, 171-183.

Lau, K.-M., and H. Weng, 1995: Climate signal detection using wavelet transform: How to make a time series sing. Bull. Amer. Meteor. Soc., 76, 2391-2402.

Masuda, A., 1982: An interpretation of the bimodal character of the stable Kuroshio path. Deep-Sea Res., 29, 471-484.

Mitsudera, H., Y. Yoshikawa, B. Taguchi, and H. Nakamura, 1997: High-resolution Kuroshio/Oyashio System model: Preliminary results (in Japanese with English abstract). Japan Marine Science and Technology Center Rep. 36, 19 pp. [Available from Japan Marine Science and Technology Center, Yokosuk 237-0061, Japan.]

Nagata, Y., and K. Takeshita, 1985: Variation of the sea surface temperature distribution across the Kuroshio in the Tokara Strait. $J$. Oceanogr. Soc. Japan, 41, 244-258.

Nakano, T., I. Kaneko, and Y. Takatsuki, 1994: The Kuroshio structure estimated by the inverse method. J. Phys. Oceanogr., 24, 609618 .

Nitani, H., 1972: Beginning of the Kuroshio. Kuroshio, Physical Aspects of the Japan Current. H. Stommel and K. Yoshida, Eds., University of Washington Press, 129-164.

Oberhuber, J. M., 1988: An atlas based on the COADS Data Set. Max Planck Institute for Meteorology Tech Rep. 15. [Available from Max-Planck-Institut für Meteorologie, Bundesstr. 55, D20146 Hamburg, Germany.]

Qiu, B., 1999: Seasonal eddy field modulation of the North Pacific subtropical countercurrent: TOPEX/Poseidon observations and theory. J. Phys. Oceanogr., 29, 2471-2486.

, and W. Miao, 2000: Kuroshio path variations south of Japan:
Bimodality as a self-sustained internal oscillation. J. Phys. Oceanogr., 30, 2124-2137.

the East China Sea using satellite and in situ observational data. J. Geophys. Res., 95, 18 191-18 204.

Rikiishi, K., and K. Sasaki, 1988: Geostrophic balance of the Kuroshio as inferred from surface current and sea level observations. J. Oceanogr. Soc. Japan, 44, 305-314.

Sachs, L., 1978: Applied Statistics: A Handbook of Techniques. Springer-Verlag, 706 pp.

Stammer, D., 1997: Steric and wind-induced changes in TOPEX/ POSEIDON large-scale sea surface topography observations. $J$. Geophys. Res., 102, 20 987-21009.

Takematsu, M., K. Kawatate, W. Koterayama, T. Suhara, and H. Mitsuyasu, 1986: Moored instrument observations in the Kuroshio south of Kyushu. J. Oceanogr. Soc. Japan, 42, 201-211.

Uchida, H., S. Imawaki, and J. Hu, 1998: Comparison of Kuroshio surface velocities derived from satellite altimeter and drifting buoy data. J. Oceanogr., 54, 115-122.

Wimbush, M., H. Ichikawa, J. Book, H. Uchida, and H. Kinoshita, 1998: Separating baroclinic and barotropic sea-surface height components in the ASUKA region, by combining altimeter and inverted echo sounder measurements. Proc. Symp. on OceanEarth Dynamics and Satellite Altimetry, S. Imawaki, Ed., 3350 .

Yamagata, T., and S. Umatani, 1989: Geometry-forced coherent structures as a model of the Kuroshio large meander. J. Phys. Oceanogr., 19, 130-138.

Yamamoto, H., K. Ando, and A. Misumi, 1993: Estimation of Kuroshio volume transport in the East China Sea-Based on $\mathrm{Ku}$ roshio cruise in Oct. 1989, in Oct. 1990 and in Oct. 1991 (in Japanese with English abstract). Japan Marine Science and Technology Center Rep. 30, 37-59. [Available from Japan Marine Science and Technology Center, Yokosuk 237-0061, Japan.]

— , and Coauthors, 1998: Variability of Kuroshio current in the Tokara Strait (in Japanese with English abstract). Japan Marine Science and Technology Center Rep. 37, 45 pp. [Available from Japan Marine Science and Technology Center, Yokosuk 2370061, Japan.]

Yasuda, I., J. Yoon, and N. Suginohara, 1985: Dynamics of the Kuroshio large meander: Barotropical model. J. Oceanogr. Soc. Japan, 41, 259-273. 